\title{
The Implementation of Targeted Temperature Management: An Evidence-Based Guideline from the Neurocritical Care Society
}

\author{
Lori Kennedy Madden ${ }^{1}$ (1) Michelle Hill ${ }^{2}$ Teresa L. May ${ }^{3} \cdot$ Theresa Human $^{4}$.

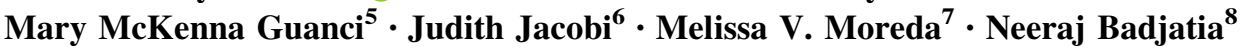

Published online: 16 October 2017

(C) Springer Science+Business Media, LLC 2017

\begin{abstract}
Background Targeted temperature management (TTM) is often used in neurocritical care to minimize secondary neurologic injury and improve outcomes. TTM encompasses therapeutic hypothermia, controlled normothermia, and treatment of fever. TTM is best supported by evidence from neonatal hypoxic-ischemic encephalopathy and out-of-hospital cardiac arrest, although it has also been explored in ischemic stroke, traumatic brain injury, and intracranial hemorrhage patients. Critical care clinicians using TTM must select appropriate cooling techniques, provide a reasonable rate of cooling, manage shivering, and ensure adequate patient monitoring among other challenges.
\end{abstract}

This guideline is endorsed by the American Association of CriticalCare Nurses (AACN), the American Association of Neuroscience Nurses (AANN) and the Society of Critical Care Medicine (SCCM).

Electronic supplementary material The online version of this article (doi:10.1007/s12028-017-0469-5) contains supplementary material, which is available to authorized users.

Lori Kennedy Madden

lkmadden@ucdavis.edu

1 University of California Davis, Sacramento, CA, USA

2 Riverside Methodist Hospital, Columbus, OH, USA

3 Maine Medical Center, Portland, ME, USA

4 Barnes Jewish Hospital, Washington University, Saint Louis, MO, USA

5 Massachusetts General Hospital, Boston, MA, USA

6 Indiana University Health Methodist Hospital, Indianapolis, IN, USA

7 Duke Raleigh Hospital, Raleigh, NC, USA

8 University of Maryland, Baltimore, MD, USA
Methods The Neurocritical Care Society recruited experts in neurocritical care, nursing, and pharmacotherapy to form a writing Committee in 2015. The group generated a set of 16 clinical questions relevant to TTM using the PICO format. With the assistance of a research librarian, the Committee undertook a comprehensive literature search with no back date through November 2016 with additional references up to March 2017. Results The Committee utilized GRADE methodology to adjudicate the quality of evidence as high, moderate, low, or very low based on their confidence that the estimate of effect approximated the true effect. They generated recommendations regarding the implementation of TTM based on this systematic review only after considering the quality of evidence, relative risks and benefits, patient values and preferences, and resource allocation.

Conclusion This guideline is intended for neurocritical care clinicians who have chosen to use TTM in patient care; it is not meant to provide guidance regarding the clinical indications for TTM itself. While there are areas of TTM practice where clear evidence guides strong recommendations, many of the recommendations are conditional, and must be contextualized to individual patient and system needs.

Keywords Targeted temperature management . Hypothermia - Normothermia - Controlled normothermia . Fever treatment . Therapeutic hypothermia - Guideline . GRADE methodology - Implementation guideline .

Shivering - Metabolism · Patient management .

Systematic review $\cdot$ Complications

\section{Introduction}

After neurologic injury, the brain is vulnerable to secondary damage from ischemia, edema, impaired metabolism, and other factors which can extend the zone of 
Table 1 Definitions

\begin{tabular}{|c|c|}
\hline $\mathrm{CA}$ & Cardiac arrest \\
\hline $\begin{array}{l}\text { Controlled normothermia } \\
\text { (NT) }\end{array}$ & Controlled and intentional reduction and/or maintenance of core body temperature between 36.0 and $37.4{ }^{\circ} \mathrm{C}$ [1] \\
\hline $\begin{array}{l}\text { Conventional cooling } \\
\text { methods }\end{array}$ & $\begin{array}{l}\text { Cold }\left(4^{\circ} \mathrm{C}\right) \text { crystalloid IV fluids, cold sponge baths, bags of ice applied directly to axillae/groin, fans, water- or air- } \\
\text { circulating blankets, iced saline or water NG lavage/bladder instillations }\end{array}$ \\
\hline $\mathrm{CPC}$ & Cerebral performance category \\
\hline $\begin{array}{l}\text { Deep/severe } \\
\text { hypothermia }\end{array}$ & Less than $28^{\circ} \mathrm{C}[2]$ \\
\hline DSMC & Data safety monitoring committee \\
\hline EEG & Electroencephalogram \\
\hline EV & Intravascular \\
\hline Fever & Core body temperature greater than $37.5^{\circ} \mathrm{C}$ (definition varies-also defined as $>38.3{ }^{\circ} \mathrm{C}$ or $>38.5{ }^{\circ} \mathrm{C}$ ) \\
\hline GCS & Glasgow Coma Scale \\
\hline GOS & Glasgow Outcome Scale \\
\hline HIE & Hypoxic-ischemic encephalopathy \\
\hline $\mathrm{H} \& \mathrm{H}$ & Hunt and Hess score \\
\hline $\mathrm{ICH}$ & Intracerebral hemorrhage \\
\hline $\mathrm{ICU}$ & Intensive care unit \\
\hline IHCA & In-hospital cardiac arrest \\
\hline IICP & Increased intracranial pressure \\
\hline IV & Intravenous \\
\hline $\begin{array}{l}\text { Longer duration } \\
\text { hypothermia }\end{array}$ & Greater than $24 \mathrm{~h}$ (cardiac arrest population); greater than $48 \mathrm{~h}$ in other populations \\
\hline LOS & Length of stay \\
\hline Mild hypothermia & $32-34{ }^{\circ} \mathrm{C}[2]$ \\
\hline MLS & Midline shift \\
\hline Moderate hypothermia & $28-32{ }^{\circ} \mathrm{C}[2]$ \\
\hline mRS & Modified Rankin score \\
\hline NIHSS & National Institutes of Health Stroke Scale \\
\hline NPARC & National Post-Arrest Research Consortium \\
\hline NS & Not significant \\
\hline $\mathrm{OHCA}$ & Out-of-hospital cardiac arrest \\
\hline Overshoot & $\begin{array}{l}\text { Temperature drop }>0.5^{\circ} \mathrm{C} \text { below target temperature [3]; Temperature } 32{ }^{\circ} \mathrm{C} \text { or lower [41]; temperature lower than } \\
\text { goal temperature }\end{array}$ \\
\hline $\begin{array}{l}\text { Prophylactic } \\
\text { hypothermia }\end{array}$ & TH started within $2.5 \mathrm{~h}$ of neurologic injury and before evidence of secondary injury (e.g., elevated ICP) \\
\hline Ppx & Prophylaxis \\
\hline RASS & Richmond Agitation-Sedation Scale \\
\hline $\mathrm{RCT}$ & Randomized controlled trial \\
\hline SAH & Subarachnoid hemorrhage \\
\hline Servo-control & Feedback mechanism to automate device temperature based on patient temperature and goal temperature \\
\hline $\begin{array}{l}\text { Shorter duration } \\
\text { hypothermia }\end{array}$ & Less than $24 \mathrm{~h}$ (cardiac arrest population); $<24-48 \mathrm{~h}$ in other populations \\
\hline $\mathrm{SOC}$ & Standard of care \\
\hline$T$ & Temperature ( $T_{\text {source }}$ identifies a specific source of measurement) \\
\hline TBI & Traumatic brain injury \\
\hline
\end{tabular}


Table 1 continued

\begin{tabular}{ll}
\hline Therapeutic hypothermia $(\mathrm{TH})$ & Controlled and intentional reduction of core body temperature to $32.0-35.9^{\circ} \mathrm{C}$ \\
TMD & Temperature modulating device \\
TOF & Train of four \\
TT & Target temperature \\
Tx & Treatment \\
Undershoot & Temperature higher than goal temperature/not achieving goal temperature
\end{tabular}

injury. Fever is often a contributor to secondary injury and is associated with greater morbidity and mortality. As such, targeted temperature management (TTM) is often used in neurocritical care to minimize secondary neurologic injury and improve outcomes. TTM is best supported by evidence from neonatal hypoxic-ischemic encephalopathy (HIE) and out-of-hospital cardiac arrest (OHCA), although it has also been explored in ischemic stroke, traumatic brain injury (TBI), and intracranial hemorrhage patients [1, 2].

TTM encompasses therapeutic hypothermia (TH), controlled normothermia, and treatment of fever (Table 1). Critical care clinicians using TTM must select appropriate cooling techniques, provide a reasonable rate of cooling, manage shivering, and ensure adequate patient monitoring among other challenges. Given the myriad of practical issues related to TTM implementation, the Neurocritical Care Society (NCS) set out to develop an evidence-based guideline regarding the use of TTM in neurocritical care using Grading of Recommendations Assessment, Development and Evaluation (GRADE) guideline methodology.

This guideline is intended for neurocritical care clinicians who have chosen to use TTM in patient care; it is not meant to provide guidance regarding the clinical indications for TTM itself. For such information, readers should review specific guidelines for the application of TTM developed for stroke [3-6], cardiac arrest [7, 8], HIE [9], and traumatic brain injury $[10,11]$ patient populations. The use of TTM in the operative setting was not reviewed.

\section{Methods}

Experts in neurocritical care, nursing, and pharmacotherapy were recruited from within the NCS to form a writing Committee, and a preliminary organizational meeting was held in Scottsdale, Arizona in September 2015. Using the GRADE framework, the Committee generated a set of 16 clinical questions relevant to TTM specifying the patient group of interest, the intervention, the comparators, and the outcomes of interest (Population-Intervention-ComparisonOutcomes [PICO] format). With the assistance of a research librarian, the Committee undertook a comprehensive literature search of the PubMed, CINAHL PLUS, Embase, Cochrane Library, and Joanna Briggs Institute Evidence-Based Practice databases with no back date through November 2016. Also included for analysis were articles identified in bibliographies and personal files which included references up to March 2017.

The Committee did not consider articles in languages other than English, non-human studies, or unpublished presentations. The Committee considered systematic reviews, meta-analyses, randomized controlled trials, and observational studies which specifically addressed the PICO variables. Neonatal and pediatric studies were included where applicable. At least two Committee members reviewed the abstracts from the electronic search for relevance, and full-text articles were obtained where applicable. The full search strategy is provided in the supplementary materials (Appendix in ESM).

The Committee utilized GRADE methodology to adjudicate the quality of evidence as high, moderate, low, or very low based on their confidence that the estimate of effect approximated the true effect. They generated recommendations only after considering the quality of evidence, relative risks and benefits, patient values and preferences, and resource allocation [12]. The Committee formulated recommendations for or against an intervention, and classified them as strong ("we recommend") or conditional ("we suggest"). Strong recommendations are the preferred course of action for most patients and should be adopted as policy in most situations. Conditional recommendations require further consideration within the clinical and institutional context and should be carefully evaluated by stakeholders before being implemented as policy [13].

In addition to offering recommendations based on the formal GRADE process, the Committee identified areas of practice where there is insufficient evidence to support recommendations and opted to provide "good practice statements" to address these issues. These statements are meant to serve as clinical guidance where there is a high level of certainty regarding overall benefit (or harm), but a lack of published evidence. 
The full Committee met on January 10-11, 2017, in Denver and again on March 24-25, 2017, in Boston. Topic authors presented GRADE evidence summaries, and recommendations were arrived at after discussion by the entire panel. Both internal experts from the Neurocritical Care Society and external stakeholders reviewed the final guideline.

\section{Induction and Maintenance of TTM}

\section{Does a Pre-defined Duration of TTM Result in Similar Outcomes as Goal-Directed Therapy?}

While the Committee wished to address the relative benefits of a pre-specified duration of TTM versus a goaldirected duration of therapy, few publications examine this specific issue and professional societies have endorsed a range of practices [8, 14, 15]. Four studies met inclusion criteria to address this question and all focused on therapeutic hypothermia rather than controlled normothermia. The Committee defined favorable neurologic outcome and mortality as the outcomes of primary interest in these studies, and the overall quality of evidence was moderate.

In terms of neurologic outcome, two observational trials examined OHCA and one randomized controlled trial (RCT) studied TBI [16]. In both OHCA studies, post hoc analysis was used to identify variables that were associated with favorable outcomes. A correlation was noted between improved survival and a longer duration of therapy; however, this may be related to the earlier application of TTM post-arrest as opposed to the duration of therapy itself $[17,18]$. While studying intracranial pressure (ICP) control in severe TBI patients, Jiang found TTM for five days as opposed to two days resulted in significantly improved functional outcomes [16].

Two studies addressed mortality as a function of TTM duration. An RCT of neonates with hypoxic-ischemic encephalopathy (HIE) randomized to 72 or $120 \mathrm{~h}$ of TTM at either 33.5 or $32.0{ }^{\circ} \mathrm{C}$ was stopped owing to safety concerns with longer or deeper hypothermia [19]. However, an OHCA study observed lower mortality in patients cooled for longer durations [17].

Recommendations

We suggest at least $24 \mathrm{~h}$ of cooling in OHCA patients

(Conditional recommendation, moderate quality evidence)

We suggest longer duration TTM for severe TBI patients should ICP control be the goal

(Conditional recommendation, low-quality evidence)

We advise against longer $(>72 \mathrm{~h})$ or deeper $\left(<32.0^{\circ} \mathrm{C}\right)$

hypothermia in neonates with HIE

(Conditional recommendation, moderate-quality evidence)

See Evidentiary Table 1 of Electronic Supplementary Material
Does Prophylactic Initiation of TTM Result in Similar Outcomes as Symptom-Based Initiation?

TTM can be initiated prior to evidence of secondary neurologic injury as opposed to reactively after other management strategies have failed. The Committee sought to determine whether there was any benefit to a prophylactic approach in terms of the following outcomes of primary interest: secondary neurological injury (in this context, defined as ICP burden and/or fever burden), ICU length-of-stay (including duration of sedation and/or ventilation), and neurologic outcome (e.g., outcome scores or mortality). The Committee did not identify any literature which directly compared the two approaches in therapeutic hypothermia [1, 2, 20-29].

However, for controlled normothermia more evidence exists comparing prophylactic and reactive approaches. Two RCTs and one cohort study examined TTM in patients with fever refractory to conventional therapies such as antipyretics and intermittent cooling blankets [30-32]. All noted a lower fever burden in the treatment group. Puccio et al. managed fever prophylactically in a cohort of severe TBI patients; they observed a lower ICP burden with TTM prophylaxis as compared to historical controls [33].

Findings were mixed for the outcomes of duration of ICU stay and mechanical ventilation with prophylactic versus reactive normothermia. TTM patients have more tracheostomies and longer ICU LOS, but equivalent overall hospital stays [14, 15, 30, 34]. Puccio et al. compared severe TBI patients undergoing prophylactic normothermia with historical controls and suggested equivalence of infection and complication rates [33]. Limited evidence does not suggest a difference in neurologic outcomes between prophylactic and reactive normothermia [31, 32, 34], and as such the Committee could not make a recommendation on this subject.

\footnotetext{
Recommendations

We cannot recommend any specific timing of TTM initiation (prophylactic or symptom-based), due to equivocal evidence about its impact on length of stay, ICP burden, and neurologic outcome

We recommend using controlled normothermia to reduce fever burden in patients with fever refractory to conventional therapy

(Strong recommendation, moderate-quality evidence)

See Evidentiary Table 2 of Electronic Supplementary Material
} 


\section{In Neurocritical Care Patients, Which Method of TTM Achieves Fastest Time to Target?}

The preclinical literature has shown that the greatest benefits of TTM are obtained when therapy begins within hours of the neurologic insult. Studies of longer time frames between injury and TTM initiation have yielded conflicting results, suggested less robust benefits of $\mathrm{TH}$, and demonstrated a correlation between the speed with which cooling is initiated and the ultimate duration of TTM required [35]. Laboratory studies have demonstrated that the therapeutic window for hypothermia is $<6$ hours regardless of injury type and that the goal for normothermia is prophylactic and not reactive.

However, clinical studies do not support these findings and there are no defined standards for clinically meaningful endpoints. As such, the Committee agreed by consensus that even statistically significant results were not clinically relevant if the difference between time to target was $<1 \mathrm{~h}$. Overshoot was defined as surpassing the goal body temperature, which in the case of TTM is a lower temperature than goal. Conversely, undershoot was defined as a failure to achieve target temperature or achieving it more slowly than recommended.

The Committee identified several prospective controlled studies that examined time to target as a primary endpoint. Apart from one study that included a subset of normothermia patients and one that investigated neonates with HIE $[36,37]$, all the moderate- to high-quality studies investigated time to hypothermic targets across cardiac arrest and stroke patient populations [36, 38-43]. Most studies measured systemic body temperature, although two studies utilized brain temperature as a reference point.

Many of the high-quality studies reported on differences in time to target temperature between advanced temperature modulating devices (TMD) such as surface, intravascular, or intranasal devices and standard of care interventions, which varied from ice packs to air-circulating cooling blankets. These studies found that advanced cooling techniques resulted in a faster time to target temperature and were associated with higher likelihood of success in achieving target temperature. Several studies compared the difference in time to target temperature between surface and intravascular cooling techniques; however, the majority used retrospective or uncontrolled prospective cohort methodologies [44]. Two high-quality studies failed to demonstrate superiority of either technique, though the sample sizes for each study were too small to provide adequate evidence for definitive statements $[36,40]$. As a result, the Committee could not make a recommendation regarding surface versus intravascular techniques and time to target temperature or likelihood of achieving target temperature. There were no pediatric studies utilizing cooling devices to specifically address this PICO question. In neonates, one multicenter RCT found that a servo-controlled (feedback mechanism) surface cooling device resulted in a greater likelihood of achieving target temperature as compared to standard of care (80 vs. $49 \%, p<0.001$ ) [37]. This study also demonstrated a faster time to target ( 44 vs. $63 \mathrm{~min}$ ) though this was below the Committee's pre-specified limit of clinical significance.

The rapid infusion of cold $\left(4{ }^{\circ} \mathrm{C}\right)$ saline is an inexpensive and readily available technique for achieving target temperature. It has been examined as a primary modality of cooling for both induction of hypothermia and normothermia across many neurocritical care patient populations [45]. Most studies focus on the relative safety of this technique as it relates to the occurrence of pulmonary congestion and/or cardiac arrhythmias, although they are typically of low quality due to non-randomized and/or retrospective study designs [46-49]. One large prospective RCT demonstrated the superiority of a cold saline $(30 \mathrm{cc} /$ $\mathrm{kg}$ ) bolus to achieve hypothermia over standard of care in a pre-hospital setting after cardiac arrest [43]. A cold saline infusion of $1193 \pm 647 \mathrm{cc}$ led to a significantly lower initial temperature on arrival to the $\mathrm{ED}\left(34.7 \pm 35.4{ }^{\circ} \mathrm{C}\right.$, $p<0.001)$. Patients undergoing cold saline infusion were less likely to achieve ROSC ( 41.2 vs $50.6 \%, p=0.03$ ). Though not definitive, this finding is concerning and indicates that cold saline should be used with caution during cardiac arrest resuscitations. The American Academy of Neurology Practice Guidelines for reducing brain injury after CPR recommends against the use of cold saline as an adjunctive therapy in the pre-hospital setting [7].

The induction of normothermia with cold saline infusions has been examined in one prospective series of adult patients and one retrospective series of pediatric patients $[50,51]$. This latter study also provided the only evidence for the use of cold saline for either hypothermia or normothermia in a pediatric population. As a result, there was insufficient data to support a recommendation of cold saline infusions for the induction of normothermia in adult neurocritical care patients or for the induction of normothermia or hypothermia in pediatric neurocritical care patients.

\footnotetext{
Recommendations

We recommend using intranasal, surface, or intravascular temperature-modulating devices and/or cold saline infusions over air cooling blankets, cooling fans, or cooling packs to achieve faster time to target temperature, improve the likelihood of achieving target temperature, and lessen the likelihood of overshoot

(Strong recommendation, high-quality evidence)

We recommend using surface cooling devices over passive air cooling and/or ice packs to increase the likelihood of achieving
} 
target temperature in neonatal patients with hypoxic-ischemic encephalopathy

(Strong recommendation, high-quality evidence)

See Evidentiary Table 3 of Electronic Supplementary Material

\section{In Neurocritical Care Patients, Which Method of TTM Causes the Least Temperature Variability?}

Temperature variability is the deviation of patient temperature outside of the goal, typically reported as mean deviation or percent of time outside of target. In assessing which method of TTM causes the least variability, the Committee specified degree of variability and overshoot of target temperature as outcomes of primary interest. Many studies on this subject used conventional methods in their comparison groups, which typically involves rapid infusions of cold crystalloids, ice packs, and fans.

All studies identified for inclusion evaluated $\mathrm{TH}$, the most relevant high-quality studies of variability were in OHCA patients $[39,40,52]$. In this population, intravascular catheters demonstrated less variability than gel pad surface devices or conventional methods (ice packs, cooling fans, "homemade" tents) [39]. Further, watercirculating sleeve devices without a servo-control mechanism demonstrated less variability than conventional cooling measures [52]. In a diverse sample of adult patients, variability was lowest in the intravascular device group, followed by air-circulating devices, gel pad surface devices, conventional cooling, and water-circulating devices [36]. In a cohort study of neonates with HIE, lowest variability was noted with whole-body cooling wraps with servo-controls [53].

Overshoot was evaluated in the OHCA population in one high-quality [41] and two lower-quality studies $[54,55]$, and in one lower-quality study of HIE neonates [56]. An RCT of OHCA patients compared gel pad surface devices to standard cooling blankets and ice bags; the risk of overshoot was significantly lower with gel pad surface devices $(\mathrm{RR}=0.24, p=0.01)$ [41]. A cohort study compared surface versus surface plus intravascular devices in OHCA patients and found that the surface-only group had more overshoot, although the groups were not equally matched in terms of severity of illness [54]. Another cohort study comparing intravascular devices to conventional measures did not observe a difference in overshoot [55].

A retrospective cohort study of neonates with HIE compared two types of water-circulating devices with servo-controls: one with gradient temperature changes and one with binary (HIGH/LOW) temperature settings [56]. Overshoot was significantly lower when using gradient temperature controls, although undershoot was also more prevalent with these devices.
Although the literature on temperature variability is of moderate to high quality, there are no direct data to support its impact on clinically important outcomes. However, it seems intuitively sensible that in therapeutic hypothermia specifically, wide temperature variability could inadvertently result in profoundly low temperatures with potentially deleterious effects on patient outcome.

\section{Recommendations}

To maintain constant patient temperature, we recommend using intravascular catheters, or gel pads if such catheters are not available

(Strong recommendation, high-quality evidence)

To minimize temperature variability in neonates with HIE, we suggest using a servo-controlled body wrap over conventional measures

(Conditional recommendation, low-quality evidence)

To minimize overshoot, we recommend gel pads over conventional measures

(Strong recommendation, moderate-quality evidence)

To minimize overshoot, we suggest using temperature modulating devices with servo-controls and gradient temperature changes

(Conditional recommendation, low-quality evidence)

See Evidentiary Table 4 of Electronic Supplementary Material

\section{In Neurocritical Care Patients Undergoing TTM, What is the Optimal Temperature Measurement Site?}

Inaccurately measured temperatures could negatively impact patient care and outcome. Several temperature monitoring sites are available for TTM, and various observational studies have examined their relative accuracies.

Historically, the gold standard in temperature monitoring has been pulmonary artery (PA) catheters. However, utilization of these devices is decreasing, leaving the question of the "next best" method. Esophageal and bladder probes best approximate the accuracy of PA catheters $[55,57,58]$. In one study using iced saline for TTM, an esophageal probe recorded a more rapid change in temperature than a bladder probe [59].

The noninvasive tympanic, axillary, and oral sites are convenient but also the least accurate [60-62]. Additionally, tympanic sources cannot be monitored continuously. The temporal artery site is accurate for initial recognition of hyperthermia but more likely to underestimate hyperthermia and/or overestimate hypothermia [61]. Tympanic and temporal artery measurement sources should not be utilized for managing TTM and do not have capabilities for continuous temperature monitoring [61]. 
Minimal evidence is available for endotracheal tube cuff temperature monitoring, noninvasive brain temperature monitoring, and femoro-iliac artery temperature monitoring, all of which have been found to be of comparable accuracy in low-quality studies. The Committee did not identify any studies using rectal temperatures in TTM and as such could not make a recommendation regarding this site.

\section{Recommendations \\ We suggest using an esophageal temperature probe during all phases of TTM. If an esophageal probe is not appropriate or available, we suggest using a bladder temperature probe \\ (Conditional recommendation, low-quality evidence) \\ Clinicians should monitor temperature continuously during TTM \\ (Good practice statement) \\ See Evidentiary Table 5 of Electronic Supplementary Material}

\section{Shivering}

Shivering is the body's thermoregulatory response to changes in temperature, and it increases metabolism, oxygen consumption, energy expenditure, and the production of carbon dioxide [63-65]. If not managed, shivering may negate the neuroprotective benefits of TTM.

\section{In Neurocritical Care Patients Undergoing TTM, Should Shivering be Assessed Using Standardized Tools?}

The detection of shivering is challenging. Currently, there is no continuous monitoring device that detects and/or quantifies shivering or microshivering, although several studies have introduced standardized tools that may be beneficial. The Bedside Shiver Assessment Scale (BSAS) grades patient shivering using muscle group movements, is independently correlated with several calorimetric measures, and has high inter-rater reliability [63, 66]. Testing the reliability of the scale in patients with higher BSAS scores is challenging due to the ethical mandate to minimize shivering when it is observed. The BSAS has been widely applied as a shivering tool during TTM; however, it relies on subjective scoring and the vigilance of the bedside clinician.

May et al. prospectively compared electromyography (dEMG) and the BSAS in 38 survivors of OHCA; dEMG values correlated reasonably well with the BSAS scores [67]. A dEMG of 27 decibels (dB) correlated with BSAS of 0 , and $30.5 \mathrm{~dB}$ correlated with a BSAS of 1 . The dEMG for a BSAS greater than one was significantly different from BSAS of zero. While this study was limited by low patient numbers and potential lack of generalizability to other populations, dEMG may prove promising as a more objective continuous measurement.

Two other studies describe novel approaches to shiver detection, but their methodological limitations precluded the Committee from incorporating them into their recommendations. Sund-Levander found an association between an increased tympanic-toe temperature gradients and shivering [68]. Earp et al. investigated the use of pulmonary and bladder catheter ratios to detect shivering in cardiac surgery patients [69]. A ratio of less than one was indicative of shivering; however, the researchers concluded this was in part due to limitations of known physiologic temperature differences between the pulmonary artery and bladder.

Shivering must be identified and quantified using consistent language for TTM to be safely and effectively incorporated into patient care. Despite the subjective limitations of the BSAS, it provides common language and has enabled research investigation and bedside evaluation of pharmacologic and non-pharmacologic patient shivering interventions [70-75]. More research is needed to develop objective measurement tools.

\section{Recommendations \\ Clinicians and researchers should consider using a shivering assessment tool \\ (Good practice statement) \\ Of the tools available, we recommend the BSAS because of its established accuracy and inter-rater reliability \\ (Strong recommendation, moderate quality evidence) \\ See Evidentiary Table 6 of Electronic Supplementary Material \\ In Neurocritical Care Patients Undergoing TTM, does Treatment of Shivering Result in Similar Functional Outcomes as Compared to No Treatment?}

Shivering is an anticipated consequence and potentially major adverse effect of TTM [76-78]. Even mild hypothermia can elicit a vigorous thermoregulatory defense to maintain body temperature at the hypothalamic set point. Control of shivering is essential for effective cooling, as shivering combats the cooling process and makes attaining target temperature difficult in addition to increasing systemic and cerebral energy consumption and metabolic demand [79]. Pharmacologic and non-pharmacologic modalities are commonly employed in this population; however, much of the research has been 
conducted in healthy volunteers and in the immediate postoperative period [80].

Numerous studies evaluating pharmacological agents for reduction of vasoconstriction and shivering thresholds have been conducted and lay the groundwork for possible therapies. A recent meta-analysis by Park et al. found significant heterogeneity in the literature with respect to trial designs, interventions, and results when assessing pharmacologic anti-shivering therapies [81]. Sedatives and hypnotics including midazolam, lorazepam, diazepam, dexmetomidine, propofol, and buspirone have shiver threshold reductions ranging from 0.5 to $2.4{ }^{\circ} \mathrm{C}$ when used alone and many are effective in synergistic combinations [82-92]. Analgesic agents such as nefopam, alfentanil, fentanyl, and meperidine have also been evaluated both as monotherapy and in combinations [93-99]. Meperidine appears to be the most beneficial of all opioids with reported reductions in shiver thresholds between 1.2 and $2.2{ }^{\circ} \mathrm{C}[98,99]$. Magnesium mildly reduces shiver thresholds; high-dose clonidine has also shown benefit but may cause bradycardia and hypotension [93, 100-102]. Lastly, neuromuscular blocking agents (NMBAs) are widely reported to cause complete cessation of shivering but there is conflicting data regarding mortality outcomes [103-112]. NMBAs have no sedative, amnestic, or analgesic properties and should only be used in patients who are receiving adequate sedation and analgesia [113]. Ondansetron, doxapram, tramadol, naloxone, nalbuphine, and dantrolene have shown minimal shiver reductions in healthy individuals [114-116].

When using any pharmacologic agent for shiver reduction, clinicians must consider the potential variation in their pharmacokinetics and pharmacodynamics during hypothermic conditions and monitor for efficacy (shiver control) and safety (adverse drug reactions, drug interactions, drug accumulation). Of note, some studies of shiver control $[93,100,101]$ were conducted on non-brain-injured patients and there may be differing effects depending upon the location and severity of brain injury (e.g., thalamic and brain stem injury).

Non-pharmacologic interventions include skin warming techniques, head coverings, and hand, arm, face, and airway warming. All interventions have been shown to decrease the shiver index and improve overall subjective comfort in healthy volunteers [89, 117-121]. Badjatia et al. evaluated cutaneous counterwarming with air-circulating blankets and found a significant reduction in shivering, resting energy expenditure, oxygen consumption, and carbon dioxide production in patients undergoing TTM [122]. Non-pharmacologic interventions may be the optimal firstline therapy as there is no risk of sedation or drug interactions, although they may have limited capacity for shiver reduction in patients cooled to normothermia as opposed to hypothermia. Non-pharmacologic interventions should be considered in combination with pharmacologic methods when shivering cannot be controlled with non-pharmacologic measures alone.

There is strong evidence that creating and following an institutional algorithm for the assessment and treatment of shivering in TTM is an effective strategy to minimize oversedation and avoid paralytics [70, 94]. Using a validated monitoring tool and a combination of non-pharmacologic and pharmacologic therapies in an additive stepwise approach has been shown to be an effective tactic. However, there is insufficient evidence to support superiority of one treatment modality or specific escalation protocol to combat shivering.

Good practice statements

Clinicians should treat shivering promptly

We suggest a stepwise approach to shivering which prioritizes non-sedating interventions (acetaminophen, counterwarming, magnesium) over narcotic analgesics, sedatives, or paralytics

See Evidentiary Table 7 of Electronic Supplementary Material

\section{In Neurocritical Care Patients Undergoing TTM, is Metabolic Demand Similar to Patients Not Undergoing TTM?}

One of the primary mechanisms by which TTM can prevent secondary injury is by reducing metabolic demand. Cerebral metabolic rate of oxygen $\left(\mathrm{CMRO}_{2}\right)$ is tightly linked to temperature, with a $1{ }^{\circ} \mathrm{C}$ change in temperature resulting in up to $5-7 \%$ change in $\mathrm{CMRO}_{2}$. As such, TTM can modify many of the processes that are regulated by metabolic rate, including production of free radicals, inflammation, and cerebral blood flow.

In the clinical literature, there is a relative lack of highquality studies and as a result a paucity of strong translational evidence for experimental studies. The Committee only identified two studies that systematically investigated the impact hypothermia has upon measures of $\mathrm{CMRO}_{2}$ [123, 124]. Both utilized jugular venous sampling to estimate the metabolic rate and change in either jugular oxygen saturation or lactate levels associated with cooling. The impact in this small sample set was unclear and a broader discussion of the meaning of these surrogate end points of cerebral metabolism can be found in the NCS multimodality monitoring consensus statement [125].

Most hypothermia studies examine systemic metabolism as measured by resting energy expenditure (REE). These studies were conducted across stroke, TBI, and cardiac arrest populations and generally found a reduction in energy expenditure with cooling [126-130]. Likewise, two 
studies found cooling had an impact on protein catabolism, as measured by urine urea nitrogen $[131,132]$. Conclusions from both sets of studies have potential implications regarding appropriate nutritional delivery during cooling, though further evidence is required to make any recommendations. There is insufficient evidence to make a recommendation regarding the use of TTM to change measures of cerebral or systemic metabolic demand in pediatric patients.

There were far fewer studies reporting on the impact of normothermia on measures of metabolism. Hata et al. noted a consistent reduction in oxygen consumption with the application of surface temperature-modulating devices, so long as shivering was adequately controlled [131]. Osuka et al. noted that in TBI patients maintained at normothermia with chemical paralysis and moderate sedation, there was a reduction in measured REE as compared to predicted REE, with potential implications regarding nutritional estimation [132]. Two studies reported a general reduction in the rate of metabolic crises or improvement in lactate-to-pyruvate ratios with induced normothermia in TBI and subarachnoid hemorrhage $(\mathrm{SAH})$ populations $[64,133]$. There were no studies reporting the impact of normothermia on protein catabolism. All of these studies provide a very low quality of evidence regarding normothermia targets. There is insufficient evidence to recommend whether metabolic demand is similar for pediatric patients undergoing TTM [134]. Furthermore, none of the studies investigated the impact markers of metabolic demand had upon outcome measures, resulting in insufficient evidence to make a recommendation regarding the modulation of metabolic response via TTM to improve measures of outcome such as length of stay, morbidity, or mortality.

Good practice statement

Clinicians should be aware of the impact that TTM may have upon metabolism and substrate utilization. Metabolic support should be driven by the disease state and actual measurement of metabolism

See Evidentiary Table 8 of Electronic Supplementary Material

\section{Complications}

\section{In Neurocritical Care Patients, What is the Impact of TTM on GI Complications?}

Despite a reduction in overall net metabolic demand, patients likely still incur an energy deficit during TTM if no feeding is provided [63, 128]. Complications of enteral feeding during TTM may include slowed motility, high residuals, aspiration, and poor absorption, although only five studies provide some comparison between those receiving and not receiving TTM.

One observational study of thirteen patients with intracranial hemorrhage compared the tolerability of trophic enteral feeds during TTM with standard feeds in normothermic controls. Three of six patients in the mild hypothermia group had gastric residuals above $250 \mathrm{cc}$, and one patient had a mild ileus. No other adverse events were noted [130]. An additional observational study evaluated enteral tolerance in 55 cardiac arrest patients receiving TTM, and the proportion of feeds tolerated was 71,95 , and $100 \%$ on days 1,2 , and 3 , respectively [135].

Given the lack of evidence of increased adverse events in this population and the known harm of inadequate nutrition for critically ill patients in general, we suggest initiating enteral nutrition in TTM patients. In accordance with existing guidelines, nutrition support therapy with EN should be initiated within $24-48 \mathrm{~h}$ in neurocritical care patients undergoing TTM [136].

\section{Recommendation \\ We suggest that no additional measures be considered to avoid gastric intolerance in patients undergoing TTM \\ (Conditional recommendation, low-quality evidence) \\ See Evidentiary Table 9 of Electronic Supplementary Material \\ In Neurocritical Care Patients Undergoing TTM, Should Clinicians be More Vigilant for Infection and/or Interpret Laboratory Markers of Infection Differently?}

The interpretation of diagnostic testing can depend upon the pretest probability of disease, and as such the Committee reviewed the relative rates of infection in TTM patients. Three moderate- or high-quality studies were identified, although screening protocols and definitions of infection varied substantially among them and none were powered to address the incidence of infection. One RCT of pneumonia in post-arrest patients found no significant difference between hypothermic patients and normothermic controls [20]. The same was found for a separate RCT comparing hypothermia to relative normothermia [137]. A retrospective cohort study of cardiac arrest patients found that TTM is an independent risk factor for early onset pneumonia, although the retrospective nature and possible selection bias of TTM make the results difficult to interpret [138]. One other RCT of TBI patients found a greater incidence of pneumonia and meningitis although there were serious risks of bias, imprecision, inconsistency, and indirectness [139]. In summary, the highest quality evidence does not indicate a significant difference in rates of 
infection and observational studies showing a difference have serious limitations.

The influence of temperature management on inflammatory markers could potentially hinder the reliable diagnosis of infection in TTM patients. Although many studies have described the inflammatory milieu in TTM [16, 140, 141], few have provided a comparison group and even fewer have provided a comparison group in the setting of infection [142-144]. The Committee identified two retrospective case-control studies and one RCT that evaluated indicators of infection in the setting of TTM, although their retrospective nature, risk of bias, and imprecision rendered the evidence low or very low quality. The data suggest that clinical and non-clinical markers of infection (such as leukocyte count, c-reactive protein, procalcitonin, and heatshock proteins) do change in response to infection in hypothermic patients [139, 145, 146]. As such standard critical care guidelines are appropriate to monitor for infection in TTM $[147,148]$. Although some centers monitor water temperature on servo-control devices as an indicator of infection, we could find no suitable literature to guide a recommendation for this practice.

\begin{tabular}{l}
\hline Recommendation \\
\hline We suggest that clinicians adhere to standard critical care \\
guidelines when monitoring for infection in patients undergoing \\
TTM \\
(Conditional recommendation, low-quality evidence) \\
See Evidentiary Tables 10 a and 10 of Electronic Supplementary \\
Material
\end{tabular}

\section{Are Laboratory Parameters Altered in Neurocritical Care Patients Receiving TTM?}

With its considerable effects on physiology, TTM has the potential to impact the accuracy and interpretation of laboratory tests commonly used in neurocritical care. The Committee focused on accuracy of potassium, arterial blood gas (ABG), creatinine, and glucose in the setting of TTM.

Hypothermia induces hypokalemia by shifting potassium from the extracellular to intracellular or extravascular spaces. Mirzoyev et al. reported potassium levels decrease as the core temperature decreases where patients cooled to a goal temperature of $33{ }^{\circ} \mathrm{C}$ showed a potassium nadir of $3.2 \pm 0.7 \mathrm{mmol} / \mathrm{L}$ at $10 \mathrm{~h}$ after cooling initiation [149]. Nielsen et al. reported that $13 \%$ and $18 \%$ of patients cooled to 36 and $33{ }^{\circ} \mathrm{C}$, respectively, had hypokalemia [137]. Furthermore, there appears to be a correlation between nadir potassium levels $<3.0 \mathrm{mmol} / \mathrm{L}$ and risk of premature ventricular contractions [149].
Rebound hyperkalemia is of concern during rewarming as potassium is shifted back to the extracellular space. Hyperkalemia and cardiac arrhythmias have been associated with maintaining potassium levels above $3.5 \mathrm{mmol} / \mathrm{L}$ during the cooling maintenance phase [150]. Therefore, maintaining serum potassium levels between 3.0 and $3.5 \mathrm{mmol} / \mathrm{L}$ during induction and maintenance phases may prevent arrhythmias and reduce the risk of rebound hyperkalemia during rewarming.

Since the partial pressures of gases change with temperature, the accuracy of ABG values during hypothermia has often been questioned. One observational study comparing the alpha-stat to the $\mathrm{pH}$-stat method found that the latter improved identification of hypoxemia and hypercapnia, which led to better patient outcomes [151]. It should be noted that $\mathrm{pH}$-stat-guided ventilation management may lead to an increase in ICP [139]. Given the paucity of clinical trial data, there is insufficient evidence to recommend either alpha-stat or $\mathrm{pH}$-stat methodology to aid in the management of ventilation during TTM. Nevertheless, correcting $\mathrm{ABG}$ values for actual body temperatures using either method will result in the most accurate assessment of partial pressure of oxygen and carbon dioxide.

The ability to diagnose renal dysfunction is critical in both dosing of medications and estimated clearance of medications, especially with medications that may alter the neurologic exam. Zeiner et al. compared serum creatinine and creatinine clearance in post-arrest TTM patients and controls. In the TTM group, both serum creatinine and creatinine clearance were reduced at $24 \mathrm{~h}$, suggesting that serum creatinine is not a reliable marker for renal function in this group of patients [152].

Hypothermia alters insulin secretion and glucose control, although little is known about how fluctuations in glucose control influence outcome. The largest study to date is a randomized trial which compared normothermia and hypothermia in 905 patients; there was no significant difference in the rates of hypoglycemia [137]. In contrast, Zhao et al. randomized TBI patients to normothermia or mild hypothermia, and mean glucose was lower in the hypothermia group [153]. Blood glucose greater than $180 \mathrm{mg} / \mathrm{dL}$ was an independent predictor of poor neurologic outcome. A prospective observational study found that glucose levels, glucose variability, and insulin requirements were higher in hypothermia maintenance phase as compared to the rewarmed normothermia phase [154]. The investigators suggest that glucose variability is an independent predictor of in-hospital mortality and poor neurologic outcome. A retrospective chart review of 21 post-arrest TTM patients showed an association between a mean blood glucose greater than $220 \mathrm{mg} / \mathrm{dl}$ and decreased survival. However, if insulin therapy was instituted there 
was no significant difference in mortality [155]. In its totality, the evidence surrounding the impact of TTM on glucose control is inconsistent, and as such the Committee suggests frequent monitoring of blood glucose as the most prudent approach.

Recommendations

We recommend maintaining serum potassium levels between 3.0 and $3.5 \mathrm{mmol} / \mathrm{L}$ during induction and maintenance phases to prevent rebound hyperkalemia and arrhythmias during rewarming

(Strong recommendation, high-quality evidence)

Arterial blood gas measurements should be temperature-corrected (Good practice statement)

Clinical monitoring for other laboratory abnormalities during cooling should be similar to that for any critically ill patient

(Good practice statement)

See Evidentiary Table 11 of Electronic Supplementary Material

\section{In Neurocritical Care Patients, does TTM Affect the Pharmacokinetics and Pharmacodynamics of Medications?}

Therapeutic hypothermia as a subset of TTM has been studied for its impact on the pharmacokinetics (PK) of various drugs. Significant inter-individual variation in PK parameters is not surprising considering concurrent changes in hemodynamics and organ systems that may accompany cardiac arrest or TBI and resuscitation [156]. Hypothermia reduces the activity of metabolic processes, including absorption, distribution, and excretion. Passive processes of drug disposition (diffusion or paracellular diffusion) do not seem to be significantly altered [156].

During TH, intestinal drug absorption is reduced and gastric emptying may be delayed. Antiplatelet agents illustrate this effect. Concentrations of parent drug and metabolites are reduced in cardiac arrest patients receiving TH and clopidogrel via a nasogastric (NG) tube [157-159]. Crushing tablets for NG tube administration may also reduce bioavailability. The desired inhibition of platelet aggregation with clopidogrel, ticagrelor, or prasugrel may not be as reliable in $\mathrm{TH}$ patients, increasing the risk for stent thrombosis [158, 160, 161]. Ticagrelor and prasugrel appear to be preferred agents during $\mathrm{TH}$, although IV cangrelor can circumvent concerns regarding absorption [160, 162, 163].

Hepatic drug enzymatic metabolism (cytochrome P450) is reduced during $\mathrm{TH}$, impacting sedative and analgesic medications. With $24 \mathrm{~h}$ of cooling, midazolam concentrations are unchanged, but concentrations increase significantly after several days of $\mathrm{TH}$, due to reduced
CYP3A4 activity [164, 165]. In TBI patients with TH, estimated PK parameters suggest that the half-life of midazolam may approach $7000 \mathrm{~h}$ after several days of cooling at a core temperature $<35^{\circ} \mathrm{C}$ [164]. Initiation of rewarming increases the clearance of midazolam $[164,165]$. Altering midazolam doses, and similarly the doses of morphine, propofol, or remifentanil during TH to prevent excessive or prolonged drug effect does not appear to be necessary unless the duration of cooling is prolonged [165-167]. High extraction drugs like lidocaine or propofol are influenced by hepatic perfusion. Reduced blood flow related to cardiac injury or a negative inotropic effect of the drug can reduce the metabolism of these drugs, but TH alone has not been shown to reduce hepatic perfusion [168]. Fentanyl clearance is also reduced during TH, but unlike other sedatives, serum concentrations do not decline with rewarming, possibly related to the long half-life relative to the rewarming period $[165,166]$.

Reduced hepatic metabolism via CYP3A4 also impacts the neuromuscular blocking agents vecuronium and rocuronium during TH $[157,169,170]$, although a change in PD was not demonstrated with vecuronium [157]. Atracurium also has reduced clearance during cooling of surgical patients, leading to potential delay in recovery of neuromuscular function. The effect of rewarming on drug metabolism has not been reported [167]. Changes in Phase II metabolism during TH have not been observed, with the exception of morphine clearance which changes in a manner similar to midazolam $[165,166]$.

The effect of TH on plasma protein binding is poorly studied, although $\mathrm{TH}$ to $34{ }^{\circ} \mathrm{C}$ did not change phenytoin binding to albumin [171]. Hepatic metabolism of phenytoin via CYP2C9 and CYP2C19 is a saturable process at high concentrations. Phenytoin accumulates during TH, but concentrations fall during rewarming. [172, 173]. Considering this, it is prudent to monitor phenytoin concentrations during TH. Carbamazepine, propranolol, and lidocaine bind to alpha- 1 acid glycoprotein, an acute-phase reactant that would be expected to increase after cardiac arrest or TBI, but data on additional changes during TH are not available. The central volume of distribution of neostigmine, a reversal agent for NMBAs, was reduced $38 \%$ in volunteers undergoing cooling, and time to onset of maximum effect increased by $1 \mathrm{~min}$, but cooling did not change clearance or duration of action [157]. Propofol and midazolam are also potentially influenced by alterations in drug distribution due to reduced partitioning to peripheral compartments, increasing the serum concentration [156, 168].

Changes in glomerular filtration rate are not expected from $\mathrm{TH}$ alone, although drugs that depend on renal elimination for clearance may be impacted due to changes in tubular secretion. Heparin is partially cleared by renal 
mechanisms, especially at high doses, and its anticoagulant activity requires interaction with cofactor antithrombin III. The use of typical weight-based heparin doses may produce an exaggerated aPTT response in TH patients, but the exact PK mechanism (enzyme activity, protein binding, or filtration) has not been elucidated [174, 175]. Lower initial bolus and infusion doses of heparin have been suggested during $\mathrm{TH}$ with close monitoring for changing heparin requirements during rewarming. A prospective trial of proposed dosing strategies is needed. Low molecular weight heparins are administered via subcutaneous injection, and absorption may be reduced by low perfusion to the skin, especially proximal to surface cooling. Renal filtration of the LMWH products is their primary mechanism of elimination, but clinical trials of effectiveness and safety during TH have not been done.

In summary, there is insufficient evidence to recommend specific dosing strategies or routes of administration for analgesics and sedatives during $\mathrm{TH}$.

\footnotetext{
Good practice statements

As with standard intensive care practice, clinicians should monitor the therapeutic efficacy of drugs and measure serum concentrations where possible

Given that the pharmacokinetics of commonly used analgesics and sedatives may be altered by cooling, clinicians should consider their potentially long-lasting impact on neurologic assessments during TTM

See Evidentiary Table 12 of Electronic Supplementary Material
}

\section{In Neurocritical Care Patients, does TTM Affect the Incidence of Bleeding?}

The impact of temperature-related coagulopathies is of great concern in TTM. Temperatures below $35{ }^{\circ} \mathrm{C}$ are known to affect the coagulation cascade as well as platelet function, which can cause prolonged prothrombin and partial thromboplastin times [176]. As a result, it can be challenging to differentiate injury-induced coagulopathies from those caused by TTM. A small RCT analyzing the impact of body temperature on thromboelastography and platelet aggregation found no influence on results within a range of $33-37{ }^{\circ} \mathrm{C}$, suggesting a possible alternative method for assessing coagulation and platelet aggregation [177].

The Committee identified several studies in cardiac arrest, TBI, and ischemic stroke populations that assessed the impact of hypothermia on the occurrence of systemic and central nervous system (CNS) bleeding. Two metaanalyses in cardiac arrest populations undergoing hypothermia treatment demonstrated higher rates of thrombocytopenia and subsequent transfusion of blood products without a difference in the rate of bleeding [178, 179]. In TBI, none of the multicentered RCTs demonstrated a significant increase in the rate of systemic or CNS bleeding in patients treated with hypothermia $[21,24]$. In ischemic stroke patients, several single-center non-randomized trials did not demonstrate an increased risk of bleeding with hypothermia with either surface or intravascular techniques [180]. Results from the multicenter RCT Intravascular Cooling in the Treatment of Stroke 2 trial did not demonstrate a higher rate of bleeding in patients cooled with or without intravenous tissue plasminogen activator (tPA) [28]. None of these studies demonstrated a higher rate of mortality due to hemorrhagic complications. In addition, there was insufficient evidence available to make recommendations regarding the risk of bleeding and various cooling modalities.

Regarding bleeding in SAH patients, there are data supporting the safety of TTM during aneurysm surgery; however, only small retrospective case series examine the sustained use of hypothermia during the subsequent ICU stay [181, 182]. Though small case series indicate no difference in bleeding rates with hypothermia after intracerebral hemorrhage and spinal cord injury, there are currently no prospective RCTs assessing the impact of hypothermia on the rate of hemorrhage. It is important to note that none of the studies reviewed conducted a comparative analysis to assess whether the incidence of bleeding was different between surface or intravascular techniques, beyond the inherent risk of intravenous line placement.

Recommendations

We strongly recommend no change in routine care with respect to monitoring for bleeding and preventing thrombosis in TTM patients

(Strong recommendation, high-quality evidence)

We suggest that thromboelastometry may be helpful in measuring coagulation and platelet aggregation in TTM patients

(Conditional recommendation, low-quality evidence)

See Evidentiary Table 13 of Electronic Supplementary Material

\section{In neurocritical Care Patients does TTM Affect Early Mobilization?}

Early mobilization in the ICU decreases length of stay, ventilator days, delirium days, and readmissions [183, 184]. In stroke patients, early mobilization improves functional recovery and cognition [185]. Intensive care units have updated standards of care to include consideration of early mobilization in all patient populations [184].

A key barrier to mobilization is concern about patient safety and prevention of adverse events such as falls, 
hemodynamic instability, and the dislodgement of tubes and catheters. TTM devices and shivering management strategies can be barriers to early mobilization and often limit movement to range of motion exercises, turning, and elevating the head of the bed. Although there is no specific evidence regarding the safety of mobilization in TTM, Committee experts reported safely mobilizing non-intubated patients receiving normothermia or in whom shivering is well managed. This is an area of research opportunity.

Good practice statement

Clinicians should consider daily mobilization for all TTM patients

\section{Do Patients Undergoing TTM Require Special Care to Prevent Skin Complications?}

Maintenance of skin integrity and avoidance of pressure injury formation is a key quality metric in intensive care and is considered an avoidable complication. Patients undergoing TTM may be at heightened risk due to immobility and the contact of cooling devices with the skin. The Committee did not identify any prospective studies addressing this issue and relied upon retrospective case series in formulating their recommendations. In a cohort of 69 cooled cardiac arrest patients, four were noted to have skin injuries believed to be device-related. Associated variables were shock and the presence of left ventricular failure [186]. A study of surface cooling found that two of 47 patients had erythema and mottling, which was mainly associated with the use of vasopressors and shock [187]. Another report described a case of severe desquamation believed to be related to the use of a surface cooling device in a patient with congestive heart failure [188]. A multicenter retrospective cohort study failed to identify an association between a higher body mass index and skin breakdown in patients undergoing surface cooling after cardiac arrest [189].

Recommendation

We suggest increased vigilance for skin breakdown when using surface cooling devices in patients with shock or left ventricular failure

(Conditional recommendation, low-quality evidence)

See Evidentiary Table 14 of Electronic Supplementary Material

\section{In Neurocritical Care Patients Undergoing TTM, is There a Greater Incidence of Cardiac and/ or Thrombotic Complications?}

Cardiac monitoring is a low-risk intervention already in routine use for other clinical indications in neurocritical care. In adults, four RCTs failed to identify a statistically significant difference in the rate of arrhythmias between hypothermic patients and normal controls [26, 29, 190, 191]. A fifth RCT identified a significantly greater incidence of bradycardia, premature ventricular contractions, and couplets during the first $24 \mathrm{~h}$ of TTM; however, these results are of questionable clinical significance [192]. A study by De Georgia identified a $66 \%$ higher incidence of DVT with hypothermic patients [190].

In high-quality neonatal and pediatric studies, no significant difference was seen in cardiac complication rates between hypothermia and normothermia for TBI, cardiac arrest, or HIE [193-195]. Eicher et al. and Beca et al. found a higher incidence of bradycardia during hypothermia for HIE and TBI, respectively [196, 197]. Jacobs found a higher incidence of prolonged QT during hypothermia for HIE ( $p=0.006)$ [198]. As with the adult studies, bradycardia was more prevalent in hypothermic pediatric patients, but not to a clinically significant degree. Gluckman et al. found no difference in the incidence of DVT between hypothermic and normothermic patients [193].

\footnotetext{
Recommendations

We recommend cardiac monitoring during TTM, particularly during hypothermia

(Strong recommendation, high-quality evidence)

Because of the lack of evidence for increased risk, we do not recommend a change to routine monitoring for other complications, including renal failure, ARDS, GI-tract impairment, hypotension, DVT, days intubated and seizures

(Strong recommendation, high-quality evidence)

See Evidentiary Table 15 of Electronic Supplementary Material
}

\section{Resource Considerations}

TTM has considerable implications on workload, equipment needs, and financial resources, and two costeffectiveness studies have evaluated the economic impact of TTM. Merchant et al. compared neurologic outcomes in post-arrest therapeutic hypothermia and conventional care [199]. Hypothermia yielded an average gain of 0.66 quality adjusted life years (QALY) at an incremental cost of $\$ 31,254$. Gajarski et al. conducted a second cost-effectiveness analysis comparing cooling blankets, peritoneal lavage, and veno-venous extracorporeal membrane oxygenation to conventional supportive care in OHCA patients [200]. Lavage produced the highest increase in QALY (2.43) with an incremental cost-effectiveness ratio of $\$ 58,329$ per QALY when compared to cooling blankets. Both studies concluded that cooling blankets provide improved clinical outcomes with acceptable costs. There is 
a paucity in the literature evaluating newer TMDs and their cost-effectiveness.

Several surveys have reported that a lack of treatment protocols, knowledge deficiencies, limited access to dedicated equipment, reimbursement concerns, lack of financial resources, and increased workload are major barriers to TTM implementation [201-205]. Gel pad surface devices are often considered to be easier to apply and maintain, and all TMDs are considered to be less labor-intensive than conventional cooling methods. Intravascular devices are commonly considered to be more hygienic and to allow for better visualization of the patient.

\section{Conclusion}

In neurocritical care patients, TTM may have a role in reducing secondary injury and improving long-term recovery. The Committee identified areas of TTM practice where clear evidence could guide the formulation of strong recommendations. Temperature-modulating devices with servo-control mechanisms are the superior method of inducing hypothermia and avoiding sustained fever after injury, and there is evidence to suggest that temperature variability during the maintenance phase can be reduced by the use of intravascular and gel pad surface devices. Shivering should be monitored with the BSAS to better quantify shivering activity, though there is a lack of data regarding which interventions best blunt the shivering response.

Many important issues surrounding the implementation of TTM remain understudied and the lack of controlled prospective investigations posed a significant challenge for the Committee. None of the large RCTs demonstrated an increased risk in the occurrence of acute kidney injury, gastric complications, hypotension, DVT, days of mechanical ventilation or seizures with the use of TTM. High-quality evidence is lacking regarding the ideal site for temperature monitoring, the ideal duration of TTM in varying disease states, and the use of pharmacological agents during cooling. As such, many of the recommendations offered herein are conditional and must be contextualized to individual patient and system needs. Future research in these areas may allow for recommendations of greater certainty and more definitive standards of patient care.

Acknowledgements We would like to acknowledge the assistance provided by Herbert Fried (GRADE methodology), Michelle Lieggi (research librarian), and Zoe Oliver (manuscript preparation).
Disclosures Madden: none; Hill: honorariums from Bard Medical for speakers bureau; May: none; Human: honorariums from Cumberland Pharmaceuticals for advisory panel; Guanci: honorariums from Bard Medical for speakers bureau; Jacobi: none; Moreda: none; Badjatia: research funding from Bard Medical and Maryland Industry Partnership Program.

\section{References}

1. Bernard SA, Gray TW, Buist MD, Jones BM, Silvester W, Gutteridge G, Smith K. Treatment of comatose survivors of outof-hospital cardiac arrest with induced hypothermia. N Engl J Med. 2002;346(8):557-63.

2. Shankaran S, Laptook AR, Ehrenkranz RA, Tyson JE, McDonald SA, Donovan EF, Fanaroff AA, Poole WK, Wright LL, Higgins RD, et al. Whole-body hypothermia for neonates with hypoxic-ischemic encephalopathy. $N$ Engl J Med. 2005;353(15):1574-84.

3. Hemphill JC 3rd, Greenberg SM, Anderson CS, Becker K, Bendok BR, Cushman M, Fung GL, Goldstein JN, Macdonald $\mathrm{RL}$, Mitchell $\mathrm{PH}$, et al. Guidelines for the management of spontaneous intracerebral hemorrhage: a guideline for healthcare professionals from the American Heart Association/ American Stroke Association. Stroke. 2015;46(7):2032-60.

4. Connolly ES Jr, Rabinstein AA, Carhuapoma JR, Derdeyn CP, Dion J, Higashida RT, Hoh BL, Kirkness CJ, Naidech AM, Ogilvy CS, et al. Guidelines for the management of aneurysmal subarachnoid hemorrhage: a guideline for healthcare professionals from the American Heart Association/American Stroke Association. Stroke. 2012;43(6):1711-37.

5. Diringer MN, Bleck TP, Claude Hemphill J III, Menon D, Shutter L, Vespa P, Bruder N, Connolly ES Jr, Citerio G, Gress $\mathrm{D}$, et al. Critical care management of patients following aneurysmal subarachnoid hemorrhage: recommendations from the Neurocritical Care Society's Multidisciplinary Consensus Conference. Neurocrit Care. 2011;15(2):211-40.

6. Jauch EC, Saver JL, Adams HP Jr, Bruno A, Connors JJ, Demaerschalk BM, Khatri P, McMullan PW Jr, Qureshi AI, Rosenfield K, et al. Guidelines for the early management of patients with acute ischemic stroke: a guideline for healthcare professionals from the American Heart Association/American Stroke Association. Stroke. 2013;44(3):870-947.

7. Geocadin RG, Wijdicks E, Armstrong MJ, Damian M, Mayer SA, Ornato JP, Rabinstein A, Suarez JI, Torbey MT, Dubinsky RM, et al. Practice guideline summary: reducing brain injury following cardiopulmonary resuscitation: report of the Guideline Development, Dissemination, and Implementation Subcommittee of the American Academy of Neurology. Neurology. 2017;88(22):2141-9.

8. Callaway CW, Donnino MW, Fink EL, Geocadin RG, Golan E, Kern KB, Leary M, Meurer WJ, Peberdy MA, Thompson TM, et al. Part 8: post-cardiac arrest care: 2015 American heart association guidelines update for cardiopulmonary resuscitation and emergency cardiovascular care. Circulation. 2015;132(18 Suppl 2):S465-82.

9. Committee on F, Newborn, Papile LA, Baley JE, Benitz W, Cummings J, Carlo WA, Eichenwald E, Kumar P, Polin RA et al: Hypothermia and neonatal encephalopathy. Pediatrics 2014, 133(6):1146-1150. 
10. Carney N, Totten AM, O'Reilly C, Ullman JS, Hawryluk GW, Bell MJ, Bratton SL, Chesnut R, Harris OA, Kissoon N, et al. Guidelines for the management of severe traumatic brain injury, fourth edition. Neurosurgery. 2017;80(1):6-15.

11. Trauma Quality Improvement Program (TQIP). Best Practices in the Management of Traumatic BrainInjury. In: American College of Surgeons Committee on Trauma. 2015. https://www. facs.org/ /media/files/quality\%20programs/trauma/tqip/trauma tic\%20brain\%20injury\%20guidelines.ashx. Accessed Jan 2017.

12. Andrews JC, Schunemann HJ, Oxman AD, Pottie K, Meerpohl JJ, Coello PA, Rind D, Montori VM, Brito JP, Norris S, et al. GRADE guidelines: 15 . Going from evidence to recommendation-determinants of a recommendation's direction and strength. J Clin Epidemiol. 2013;66(7):726-35.

13. Guyatt GH, Oxman AD, Kunz R, Falck-Ytter Y, Vist GE, Liberati A, Schunemann HJ, Group GW: Going from evidence to recommendations. BMJ 2008, 336(7652):1049-1051,

14. Donnino MW, Andersen LW, Berg KM, Reynolds JC, Nolan JP, Morley PT, Lang E, Cocchi MN, Xanthos T, Callaway CW, et al. Temperature management after cardiac arrest: an advisory statement by the advanced life support task force of the international liaison committee on resuscitation and the American Heart Association emergency cardiovascular care committee and the council on cardiopulmonary, critical care, perioperative and resuscitation. Circulation. 2015;132(25):2448-56.

15. Kochanek PM, Carney N, Adelson PD, Ashwal S, Bell MJ, Bratton S, Carson S, Chesnut RM, Ghajar J, Goldstein B, et al. Guidelines for the acute medical management of severe traumatic brain injury in infants, children, and adolescents-second edition. Pediatr Crit Care Med. 2012;13(Suppl 1):S1-82.

16. Jiang JY, Xu W, Li WP, Gao GY, Bao YH, Liang YM, Luo QZ. Effect of long-term mild hypothermia or short-term mild hypothermia on outcome of patients with severe traumatic brain injury. J Cereb Blood Flow Metab. 2006;26(6):771-6.

17. Laish-Farkash A, Matetzky S, Kassem S, Haj-Iahia H, Hod H. Therapeutic hypothermia for comatose survivors after cardiac arrest. IMAJ. 2007;9(4):252-6.

18. Shinozaki K, Oda S, Sadahiro T, Nakamura M, Hirayama Y, Watanabe E, Tateishi Y, Nakanishi K, Kitamura N, Hirasawa H. Duration of well-controlled core temperature correlates with neurological outcome in patients with post-cardiac arrest syndrome. Am J Emerg Med. 2012;30(9):1838-44.

19. Shankaran S, Laptook AR, Pappas A, McDonald SA, Das A, Tyson JE, Poindexter BB, Schibler K, Bell EF, Heyne RJ, et al. Effect of depth and duration of cooling on deaths in the NICU among neonates with hypoxic ischemic encephalopathy: a randomized clinical trial. JAMA. 2014;312(24):2629-39.

20. The Hypothermia after Cardiac Arrest Study Group. Mild therapeutic hypothermia to improve the neurologic outcome after cardiac arrest. N Engl J Med. 2002;346(8):549-56.

21. Clifton GL, Miller ER, Choi SC, Levin HS, McCauley S, Smith KR Jr, Muizelaar JP, Wagner FC Jr, Marion DW, Luerssen TG, et al. Lack of effect of induction of hypothermia after acute brain injury. N Engl J Med. 2001;344(8):556-63.

22. Aibiki M, Maekawa S, Yokono S. Moderate hypothermia improves imbalances of thromboxane A2 and prostaglandin I2 production after traumatic brain injury in humans. Crit Care Med. 2000;28(12):3902-6.

23. Clifton GL, Allen S, Barrodale P, Plenger P, Berry J, Koch S, Fletcher J, Hayes RL, Choi SC: A phase II study of moderate hypothermia in severe brain injury. J Neurotrauma 1993, 10(3):263-271; discussion 273.

24. Clifton GL, Valadka A, Zygun D, Coffey CS, Drever P, Fourwinds S, Janis LS, Wilde E, Taylor P, Harshman K, et al. Very early hypothermia induction in patients with severe brain injury (the National Acute Brain Injury Study: hypothermia II): a randomised trial. Lancet Neurol. 2011;10(2):131-9.

25. Marion DW, Penrod LE, Kelsey SF, Obrist WD, Kochanek PM, Palmer AM, Wisniewski SR, DeKosky ST. Treatment of traumatic brain injury with moderate hypothermia. N Engl J Med. 1997;336(8):540-6.

26. Qiu WS, Liu WG, Shen H, Wang WM, Hang ZL, Zhang Y, Jiang SJ, Yang XF. Therapeutic effect of mild hypothermia on severe traumatic head injury. Chin J Traumatol. $2005 ; 8(1): 27-32$.

27. Hemmen TM, Raman R, Guluma KZ, Meyer BC, Gomes JA, Cruz-Flores S, Wijman CA, Rapp KS, Grotta JC, Lyden PD. Intravenous thrombolysis plus hypothermia for acute treatment of ischemic stroke (ICTuS-L). Stroke. 2010;41(10):2265-70.

28. Lyden P, Hemmen T, Grotta J, Rapp K, Ernstrom K, Rzesiewicz T, Parker S, Concha M, Hussain S, Agarwal S, et al. Results of the ICTuS 2 trial (Intravascular Cooling in the Treatment of Stroke 2). Stroke. 2016;47(12):2888-95.

29. Andrews PJ, Sinclair HL, Rodriguez A, Harris BA, Battison CG, Rhodes JK, Murray GD, Eurotherm Trial C. Hypothermia for intracranial hypertension after traumatic brain injury. $\mathrm{N}$ Engl $\mathrm{J}$ Med. 2015;373(25):2403-12.

30. Badjatia N, Fernandez L, Schmidt JM, Lee K, Claassen J, Connolly ES, Mayer SA. Impact of induced normothermia on outcome after subarachnoid hemorrhage: a case-control study. Neurosurgery. 2010;66(4):696-700.

31. Broessner G, Beer R, Lackner P, Helbok R, Fischer M, Pfausler B, Rhorer J, Kuppers-Tiedt L, Schneider D, Schmutzhard E. Prophylactic, endovascularly based, long-term normothermia in ICU patients with severe cerebrovascular disease: bicenter prospective, randomized trial. Stroke. 2009;40(12):e657-65.

32. Diringer MN. Neurocritical care fever reduction trial G: treatment of fever in the neurologic intensive care unit with a catheter-based heat exchange system. Crit Care Med. 2004;32(2):559-64.

33. Puccio AM, Fischer MR, Jankowitz BT, Yonas H, Darby JM, Okonkwo DO. Induced normothermia attenuates intracranial hypertension and reduces fever burden after severe traumatic brain injury. Neurocrit Care. 2009;11(1):82-7.

34. Lord AS, Karinja S, Lantigua H, Carpenter A, Schmidt JM, Claassen J, Agarwal S, Connolly ES, Mayer SA, Badjatia N. Therapeutic temperature modulation for fever after intracerebral hemorrhage. Neurocrit Care. 2014;21(2):200-6.

35. MacLellan CL, Clark DL, Silasi G, Colbourne F. Use of prolonged hypothermia to treat ischemic and hemorrhagic stroke. J Neurotrauma. 2009;26(3):313-23.

36. Hoedemaekers CW, Ezzahti M, Gerritsen A, van der Hoeven JG. Comparison of cooling methods to induce and maintain normo- and hypothermia in intensive care unit patients: a prospective intervention study. Crit Care. 2007;11(4):R91.

37. Akula VP, Joe P, Thusu K, Davis AS, Tamaresis JS, Kim S, Shimotake TK, Butler S, Honold J, Kuzniewicz M et al: A randomized clinical trial of therapeutic hypothermia mode during transport for neonatal encephalopathy. J Pediatr 2015, 166(4):856-861 e851-852.

38. Poli S, Purrucker J, Priglinger M, Ebner M, Sykora M, Diedler J, Bulut C, Popp E, Rupp A, Hametner C. Rapid Induction of COOLing in Stroke Patients (iCOOL1): a randomised pilot study comparing cold infusions with nasopharyngeal cooling. Crit Care. 2014;18(5):582.

39. Deye N, Cariou A, Girardie P, Pichon N, Megarbane B, Midez $\mathrm{P}$, Tonnelier JM, Boulain T, Outin H, Delahaye A, et al. Endovascular versus external targeted temperature management for patients with out-of-hospital cardiac arrest: a randomized. Controlled Study. Circulation. 2015;132(3):182-93. 
40. Pittl U, Schratter A, Desch S, Diosteanu R, Lehmann D, Demmin K, Horig J, Schuler G, Klemm T, Mende M, et al. Invasive versus non-invasive cooling after in- and out-of-hospital cardiac arrest: a randomized trial. Clin Res Cardiol. 2013;102(8):607-14.

41. Heard KJ, Peberdy MA, Sayre MR, Sanders A, Geocadin RG, Dixon SR, Larabee TM, Hiller K, Fiorello A, Paradis NA, et al. A randomized controlled trial comparing the Arctic Sun to standard cooling for induction of hypothermia after cardiac arrest. Resuscitation. 2010;81(1):9-14.

42. Castren M, Nordberg P, Svensson L, Taccone F, Vincent JL, Desruelles D, Eichwede F, Mols P, Schwab T, Vergnion M, et al. Intra-arrest transnasal evaporative cooling: a randomized, prehospital, multicenter study (PRINCE: pre-ROSC IntraNasal Cooling Effectiveness). Circulation. 2010;122(7):729-36.

43. Bernard SA, Smith K, Finn J, Hein C, Grantham H, Bray JE, Deasy C, Stephenson M, Williams TA, Straney LD, et al. Induction of therapeutic hypothermia during out-of-hospital cardiac arrest using a rapid infusion of cold saline: the rinse trial (rapid infusion of cold normal saline). Circulation. 2016;134(11):797-805.

44. de Waard MC, Banwarie RP, Jewbali LS, Struijs A, Girbes AR, Groeneveld AB. Intravascular versus surface cooling speed and stability after cardiopulmonary resuscitation. Emerg Med J. 2015;32(10):775-80.

45. Arulkumaran N, Suleman R, Ball J. Use of ice-cold crystalloid for inducing mild therapeutic hypothermia following out-ofhospital cardiac arrest. Resuscitation. 2012;83(2):151-8.

46. Bernard S, Buist M, Monteiro O, Smith K. Induced hypothermia using large volume, ice-cold intravenous fluid in comatose survivors of out-of-hospital cardiac arrest: a preliminary report. Resuscitation. 2003;56(1):9-13.

47. Jacobshagen C, Pax A, Unsold BW, Seidler T, Schmidt-Schweda S, Hasenfuss G, Maier LS. Effects of large volume, icecold intravenous fluid infusion on respiratory function in cardiac arrest survivors. Resuscitation. 2009;80(11):1223-8.

48. Polderman KH, Rijnsburger ER, Peerdeman SM, Girbes AR. Induction of hypothermia in patients with various types of neurologic injury with use of large volumes of ice-cold intravenous fluid. Crit Care Med. 2005;33(12):2744-51.

49. Hammer L, Vitrat F, Savary D, Debaty G, Santre C, Durand M, Dessertaine G, Timsit JF. Immediate prehospital hypothermia protocol in comatose survivors of out-of-hospital cardiac arrest. Am J Emerg Med. 2009;27(5):570-3.

50. Badjatia N, Bodock M, Guanci M, Rordorf GA. Rapid infusion of cold saline (4 degrees $\mathrm{C}$ ) as adjunctive treatment of fever in patients with brain injury. Neurology. 2006;66(11):1739-41.

51. Fink EL, Kochanek PM, Clark RS, Bell MJ. Fever control and application of hypothermia using intravenous cold saline. Pediatr Crit Care Med. 2012;13(1):80-4.

52. Rana M, J WS, Saygili E, Hameed U, Benke D, Hoffmann R, Schauerte P, Marx N, Rana OR: Comparative evaluation of the usability of 2 different methods to perform mild hypothermia in patients with out-of-hospital cardiac arrest. Int J Cardiol 2011, 152(3):321-326.

53. Hoque N, Chakkarapani E, Liu X, Thoresen M. A comparison of cooling methods used in therapeutic hypothermia for perinatal asphyxia. Pediatrics. 2010;126(1):e124-30.

54. Flint AC, Hemphill JC, Bonovich DC. Therapeutic hypothermia after cardiac arrest: performance characteristics and safety of surface cooling with or without endovascular cooling. Neurocrit Care. 2007;7(2):109-18.

55. Knapik P, Rychlik W, Duda D, Golyszny R, Borowik D, Ciesla D. Relationship between blood, nasopharyngeal and urinary bladder temperature during intravascular cooling for therapeutic hypothermia after cardiac arrest. Resuscitation. 2012;83(2):208-12.
56. Laptook AR, Kilbride H, Shepherd E, McDonald SA, Shankaran S, Truog W, Das A, Higgins RD, Optimizing Cooling S-C. Temperature control during therapeutic hypothermia for newborn encephalopathy using different Blanketrol devices. Ther Hypothermia Temp Manag. 2014;4(4):193-200.

57. Haugk M, Stratil P, Sterz F, Krizanac D, Testori C, Uray T, Koller J, Behringer W, Holzer M, Herkner H. Temperature monitored on the cuff surface of an endotracheal tube reflects body temperature. Crit Care Med. 2010;38(7):1569-73.

58. Krizanac D, Stratil P, Hoerburger D, Testori C, Wallmueller C, Schober A, Haugk M, Haller M, Behringer W, Herkner H, et al. Femoro-iliacal artery versus pulmonary artery core temperature measurement during therapeutic hypothermia: an observational study. Resuscitation. 2013;84(6):805-9.

59. Markota A, Palfy M, Stozer A, Sinkovic A. Difference Between Bladder and Esophageal Temperatures in Mild Induced Hypothermia. J Emerg Med. 2015;49(1):98-103.

60. Hasper D, Nee J, Schefold JC, Krueger A, Storm C. Tympanic temperature during therapeutic hypothermia. Emerg Med J. 2011;28(6):483-5.

61. Stelfox HT, Straus SE, Ghali WA, Conly J, Laupland K, Lewin A. Temporal artery versus bladder thermometry during adult medical-surgical intensive care monitoring: an observational study. BMC Anesthesiol. 2010;10(13):13.

62. Zeiner A, Klewer J, Sterz F, Haugk M, Krizanac D, Testori C, Losert H, Ayati S, Holzer M. Non-invasive continuous cerebral temperature monitoring in patients treated with mild therapeutic hypothermia: an observational pilot study. Resuscitation. 2010;81(7):861-6.

63. Badjatia N, Strongilis E, Gordon E, Prescutti M, Fernandez L, Fernandez A, Buitrago M, Schmidt JM, Ostapkovich ND, Mayer SA. Metabolic impact of shivering during therapeutic temperature modulation: the bedside shivering assessment scale. Stroke. 2008;39(12):3242-7.

64. Oddo M, Frangos S, Maloney-Wilensky E, Andrew Kofke W, Le Roux PD, Levine JM. Effect of shivering on brain tissue oxygenation during induced normothermia in patients with severe brain injury. Neurocrit Care. 2010;12(1):10-6.

65. Frank SM, Higgins MS, Fleisher LA, Sitzmann JV, Raff H, Breslow MJ. Adrenergic, respiratory, and cardiovascular effects of core cooling in humans. Am J Physiol. 1997;272(2 Pt 2):R557-62.

66. Olson DM, Grissom JL, Williamson RA, Bennett SN, Bellows ST, James ML. Interrater reliability of the bedside shivering assessment scale. Am J Crit care. 2013;22(1):70-4.

67. May T, Seder DB, Fraser GL, Tu C, McCrum B, Lucas L, Riker RR. Association of the Bedside Shivering Assessment Scale and derived EMG power during therapeutic hypothermia in survivors of cardiac arrest. Resuscitation. 2011;82(8):1100-3.

68. Sund-Levander M, Wahren LK. Assessment and prevention of shivering in patients with severe cerebral injury. A pilot study. J Clin Nurs. 2000;9(1):55-61.

69. Earp JK, Finlayson DC. Urinary bladder/pulmonary artery temperature ratio of less than 1 and shivering in cardiac surgical patients. Am J Crit Care. 1992;1(2):43-52.

70. Choi HA, Ko SB, Presciutti M, Fernandez L, Carpenter AM, Lesch C, Gilmore E, Malhotra R, Mayer SA, Lee K, et al. Prevention of shivering during therapeutic temperature modulation: the Columbia anti-shivering protocol. Neurocrit Care. 2011;14(3):389-94.

71. Logan A, Sangkachand P, Funk M. Optimal management of shivering during therapeutic hypothermia after cardiac arrest. Crit Care Nurse. 2011;31(6):e18-30.

72. Avery KR, O'Brien M, Pierce CD, Gazarian PK. Use of a nursing checklist to facilitate implementation of therapeutic 
hypothermia after cardiac arrest. Crit care nurse. 2015;35(1):29-37.

73. Presciutti M, Bader MK, Hepburn M. Shivering management during therapeutic temperature modulation: nurses' perspective. Crit Care Nurse. 2012;32(1):33-42.

74. Park B, Lee T, Berger K, Park SM, Choi KE, Goodsell TM, Rosengart A. Efficacy of nonpharmacological antishivering interventions: a systematic analysis. Crit Care Med. 2015;43(8):1757-66.

75. Seder DB, Van der Kloot TE. Methods of cooling: practical aspects of therapeutic temperature management. Crit Care Med. 2009;37(7):S211-22.

76. Sessler DI. Thermoregulatory defense mechanisms. Crit Care Med. 2009;37(7):S203-10.

77. Mahmood MA, Zweifler RM. Progress in shivering control. J Neurol Sci. 2007;261(1-2):47-54.

78. Boulant JA. Neuronal basis of Hammel's model for set-point thermoregulation. J Appl Physiol. 2006;100(4):1347-54.

79. Badjatia N, Kowalski RG, Schmidt JM, Voorhees ME, Claassen J, Ostapkovich ND, Presciutti M, Connolly ES, Palestrant D, Parra A, et al. Predictors and clinical implications of shivering during therapeutic normothermia. Neurocrit Care. 2007;6(3):186-91.

80. De Witte J, Sessler DI. Perioperative shivering: physiology and pharmacology. Anesthesiology. 2002;96(2):467-84.

81. Park SM, Mangat HS, Berger K, Rosengart AJ. Efficacy spectrum of antishivering medications: meta-analysis of randomized controlled trials. Crit Care Med. 2012;40(11):3070-82.

82. Callaway CW, Elmer J, Guyette FX, Molyneaux BJ, Anderson KB, Empey PE, Gerstel SJ, Holquist K, Repine MJ, Rittenberger JC. Dexmedetomidine reduces shivering during mild hypothermia in waking subjects. PLoS ONE. 2015;10(8):e0129709.

83. Hostler D, Northington WE, Callaway CW. High-dose diazepam facilitates core cooling during cold saline infusion in healthy volunteers. Appl Phys Nutr Metab. 2009;34(4):582-6.

84. Mokhtarani M, Mahgoub AN, Morioka N, Doufas AG, Dae M, Shaughnessy TE, Bjorksten AR, Sessler DI. Buspirone and meperidine synergistically reduce the shivering threshold. Anesth Analg. 2001;93(5):1233-9.

85. Nihara Y, Kikuchi T, Sonoda Y, Nakamura K, Yamaguchi K, Kakihana Y. Efficacy of dexmedetomidine and propofol on shivering during mild hypothermia after cardiovascular surgery. Eur J Anesth S. 2013;30:189-90.

86. Milne SE, James KS, Nimmo S, Hickey S. Oxygen consumption after hypothermic cardiopulmonary bypass: the effect of continuing a propofol infusion postoperatively. J Cardiothorac Vasc Anesth. 2002;16(1):32-6.

87. Lenhardt R, Orhan-Sungur M, Komatsu R, Govinda R, Kasuya Y, Sessler DI, Wadhwa A. Suppression of shivering during hypothermia using a novel drug combination in healthy volunteers. Anesthesiology. 2009;111(1):110-5.

88. Zweifler RM, Voorhees ME, Mahmood MA, Parnell M. Magnesium sulfate increases the rate of hypothermia via surface cooling and improves comfort. Stroke. 2004;35(10):2331-4.

89. Doufas AG, Lin CM, Suleman MI, Liem EB, Lenhardt R, Morioka N, Akca O, Shah YM, Bjorksten AR, Sessler DI. Dexmedetomidine and meperidine additively reduce the shivering threshold in humans. Stroke. 2003;34(5):1218-23.

90. Talke P, Tayefeh F, Sessler DI, Jeffrey R, Noursalehi M, Richardson C. Dexmedetomidine does not alter the sweating threshold, but comparably and linearly decreases the vasoconstriction and shivering thresholds. Anesthesiology. 1997;87(4):835-41.

91. Matsukawa T, Kurz A, Sessler DI, Bjorksten AR, Merrifield B, Cheng C. Propofol linearly reduces the vasoconstriction and shivering thresholds. Anesthesiology. 1995;82(5):1169-80.
92. Keegan SP, Hart KW, Adeoye OM, Bonomo JB, Lindsell CJ, Shutter L, Knight WA: Sedation and paralytic use during hypothermia after cardiac arrest. In: Neurocritical care. vol. 15; 2011: S219.

93. Alfonsi P, Passard A, Gaude-joindreau V, Guignard B, Sessler DI, Chauvin M. Nefopam and alfentanil additively reduce the shivering threshold in humans whereas nefopam and clonidine do not. Anesthesiology. 2009;111(1):102-9.

94. May T, Riker RR, Fraser GL, McCrum B, Gerst P, Stone P, Seder DB. Low-dose analgosedation during therapeutic hypothermia after cardiac arrest. Neurocrit Care. 2011;15(1):S212.

95. Alfonsi P, Passard A, Guignard B, Chauvin M, Sessler DI. Nefopam and meperidine are infra-additive on the shivering threshold in humans. Anesth Analg. 2014;119(1):58-63.

96. Taniguchi Y, Ali SZ, Kimberger O, Zmoos S, Lauber R, Markstaller M, Kurz A. The effects of nefopam on the gain and maximum intensity of shivering in healthy volunteers. Anesth Analg. 2010;111(2):409-14.

97. Riker RR, Gagnon DJ, May T, Seder DB, Fraser GL. Analgesia, sedation, and neuromuscular blockade during targeted temperature management after cardiac arrest. Best Pract Res Clin Anaesthesiol. 2015;29(4):435-50.

98. Kimberger O, Ali SZ, Markstaller M, Zmoos S, Lauber R, Hunkeler C, Kurz A. Meperidine and skin surface warming additively reduce the shivering threshold: a volunteer study. Crit Care. 2007;11(1):R29.

99. Kurz A, Ikeda T, Sessler DI, Larson MD, Bjorksten AR, Dechert M, Christensen R. Meperidine decreases the shivering threshold twice as much as the vasoconstriction threshold. Anesthesiology. 1997;86(5):1046-54.

100. Wadhwa A, Sengupta P, Durrani J, Akca O, Lenhardt R, Sessler DI, Doufas AG. Magnesium sulphate only slightly reduces the shivering threshold in humans. $\mathrm{Br} \mathrm{J}$ Anaesth. 2005;94(6):756-62.

101. Nicolaou G, Chen AA, Johnston CE, Kenny GP, Bristow GK, Giesbrecht GG. Clonidine decreases vasoconstriction and shivering thresholds, without affecting the sweating threshold. Can J Anaesth. 1997;44(6):636-42.

102. Delaunay L, Bonnet F, Liu N, Beydon L, Catoire P, Sessler DI. Clonidine comparably decreases the thermoregulatory thresholds for vasoconstriction and shivering in humans. Anesthesiology. 1993;79(3):470-4.

103. Jurado LV, Gulbis BE. Continuous infusion versus intermittent bolus dosing of vecuronium in patients receiving therapeutic hypothermia after sudden cardiac arrest. Pharmacotherapy. 2011;31(12):1250-6.

104. Salciccioli JD, Cocchi MN, Rittenberger JC, Peberdy MA, Ornato JP, Abella BS, Gaieski DF, Clore J, Gautam S, Giberson $\mathrm{T}$, et al. Continuous neuromuscular blockade is associated with decreased mortality in post-cardiac arrest patients. Resuscitation. 2013;84(12):1728-33.

105. Sladen RN, Berend JZ, Fassero JS, Zehnder EB. Comparison of vecuronium and meperidine on the clinical and metabolic effects of shivering after hypothermic cardiopulmonary bypass. J Cardiothorac Vasc Anesth. 1995;9(2):147-53.

106. Lascarrou JB, Le Gouge A, Dimet J, Lacherade JC, MartinLefevre L, Fiancette M, Vinatier I, Lebert C, Bachoumas K, Yehia A, et al. Neuromuscular blockade during therapeutic hypothermia after cardiac arrest: observational study of neurological and infectious outcomes. Resuscitation. 2014;85(9):1257-62.

107. Curtis J, Zettlemoyer G, Butler I. Neuromuscular blocking agents do not impact time to target temperature with therapeutic hypothermia. Crit Care Med. 2014;42(12):A1421. 
108. Snider J, Vandenberg M, Thomas W, Bockheim H. Post cardiac arrest therapeutic hypothermia without neuromuscular blockade vs. Continuous or intermittent neuromuscular blockade. Crit Care Med. 2012;40(12):142.

109. Fox M, Miller S, Danesh V, Health O, Liu-DeRyke X. Management of shivering with neuromuscular blocking agents during therapeutic hypothermia. Crit Care Med. 2012;40(12):235.

110. Mayer KA, Pearson DA, Heffner A, Studnek J, Wares C, Ward SL, Kraft K, Runyon M. Timing of paralytics affects "door-tocool" time in post-cardiac arrest patients. Acad Emerg Med. 2014;21(5):S98-9.

111. Tanaka H, Mochizuki T, Ode S, Ishimatsu S. Factors involved in prolonged effect of neuromuscular blockade in therapeutic hypothermia. Crit Care. 2014;18:S181.

112. Sanuth B, Wang K. Neuromuscular blockers for shivering prevention during therapeutic hypothermia post cardiac arrest. Crit Care Med. 2015;43(12):54.

113. Barr J, Fraser GL, Puntillo K, Ely EW, Gelinas C, Dasta JF, Davidson JE, Devlin JW, Kress JP, Joffe AM, et al. Clinical practice guidelines for the management of pain, agitation, and delirium in adult patients in the intensive care unit. Crit Care Med. 2013;41(1):263-306.

114. Komatsu R, Orhan-Sungur M, In J, Podranski T, Bouillon T, Lauber R, Rohrbach S, Sessler D. Ondansetron does not reduce the shivering threshold in healthy volunteers. $\mathrm{Br} \mathrm{J}$ Anesth. 2006;96(6):732-7.

115. de Witte J, Deloof T, de Veylder J, Housmans PR. Tramadol in the treatment of postanesthetic shivering. Acta Anaesthesiol Scand. 1997;41(4):506-10.

116. Greif R, Laciny S, Rajek AM, Larson MD, Bjorksten AR, Doufas AG, Bakhshandeh M, Mokhtarani M, Sessler DI. Neither nalbuphine nor atropine possess special antishivering activity. Anesth Analg. 2001;93(3):620-7.

117. Nakajima Y, Takamata A, Ito T, Sessler DI, Kitamura Y, Shimosato G, Taniguchi S, Matsuyama H, Tanaka Y, Mizobe T. Upright posture reduces thermogenesis and augments core hypothermia. Anesth Analg. 2002;94(6):1646-51.

118. Taniguchi Y, Lenhardt R, Sessler DI, Kurz A. The effect of altering skin-surface cooling speeds on vasoconstriction and shivering thresholds. Anesth Analg. 2011;113(3):540-4.

119. Sweney MT, Sigg DC, Tahvildari S, Iaizzo PA. Shiver suppression using focal hand warming in unanesthetized normal subjects. Anesthesiology. 2001;95(5):1089-95.

120. Iaizzo PA, Jeon YM, Sigg DC. Facial warming increases the threshold for shivering. J Neurosurg Anesthesiol. 1999;11(4):231-9.

121. Mort TC, Rintel TD, Altman F. The effects of forced-air warming on postbypass central and skin temperatures and shivering activity. J Clin Anesth. 1996;8(5):361-70.

122. Badjatia N, Strongilis E, Prescutti M, Fernandez L, Fernandez A, Buitrago M, Schmidt JM, Mayer SA. Metabolic benefits of surface counter warming during therapeutic temperature modulation. Crit Care Med. 2009;37(6):1893-7.

123. Nakamura T, Nagao S, Kawai N, Honma Y, Kuyama H. Significance of multimodal cerebral monitoring under moderate therapeutic hypothermia for severe head injury. Acta neurochir Suppl. 1998;71:85-7.

124. Nakamura T, Kuroda Y, Torigoe N, Abe Y, Yamashita S, Kawakita K, Kawai N, Tamiya T, Itano T, Nagao S. Cerebral metabolism monitoring during hypothermia following resuscitation from cardiopulmonary arrest. Acta Neurochir Suppl. 2008;102:203-6.

125. Le Roux P, Menon DK, Citerio G, Vespa P, Bader MK, Brophy GM, Diringer MN, Stocchetti N, Videtta W, Armonda R et al: Consensus summary statement of the International Multidisciplinary Consensus Conference on Multimodality Monitoring in
Neurocritical Care: a statement for healthcare professionals from the Neurocritical Care Society and the European Society of Intensive Care Medicine. Neurocritical care 2014, 21 Suppl 2:S1-26.

126. Bardutzky J, Georgiadis D, Kollmar R, Schwab S. Energy expenditure in ischemic stroke patients treated with moderate hypothermia. Intensive Care Med. 2004;30(1):151-4.

127. Holzinger U, Brunner R, Losert H, Fuhrmann V, Herkner H, Madl C, Sterz F, Schneeweiss B: Resting energy expenditure and substrate oxidation rates correlate to temperature and outcome after cardiac arrest - a prospective observational cohort study. Critical care (London, England) 2015, 19:128.

128. Oshima T, Furukawa Y, Kobayashi M, Sato Y, Nihei A, Oda S. Fulfilling caloric demands according to indirect calorimetry may be beneficial for post cardiac arrest patients under therapeutic hypothermia. Resuscitation. 2015;88:81-5.

129. Jalan R, SW OD, Deutz NE, Lee A, Hayes PC: Moderate hypothermia for uncontrolled intracranial hypertension in acute liver failure. Lancet 1999, 354(9185):1164-1168.

130. Dobak S, Rincon F: Enteral feeding during induced hypothermia after intracerebral hemorrhage. Neurology 2016, 86(16).

131. Hata JS, Shelsky CR, Hindman BJ, Smith TC, Simmons JS, Todd MM. A prospective, observational clinical trial of fever reduction to reduce systemic oxygen consumption in the setting of acute brain injury. Neurocrit Care. 2008;9(1):37-44.

132. Osuka A, Uno T, Nakanishi J, Hinokiyama H, Takahashi Y, Matsuoka T: Energy expenditure in patients with severe head injury: controlled normothermia with sedation and neuromuscular blockade. J Crit Care 2013, 28(2):218 e219-213.

133. Chmayssani M, Stein NR, McArthur DL, Vespa PM. Therapeutic intravascular normothermia reduces the burden of metabolic crisis. Neurocrit Care. 2015;22(2):265-72.

134. Mtaweh H, Smith R, Kochanek PM, Wisniewski SR, Fabio A, Vavilala MS, Adelson PD, Toney NA, Bell MJ. Energy expenditure in children after severe traumatic brain injury. Pediatr Crit Care Med. 2014;15(3):242-9.

135. Williams ML, Nolan JP. Is enteral feeding tolerated during therapeutic hypothermia? Resuscitation. 2014;85(11):1469-72.

136. Taylor BE, McClave SA, Martindale RG, Warren MM, Johnson DR, Braunschweig C, McCarthy MS, Davanos E, Rice TW, Cresci GA, et al. Guidelines for the provision and assessment of nutrition support therapy in the adult critically ill patient: society of critical care medicine (SCCM) and American society for parenteral and enteral nutrition (A.S.P.E.N.). Crit Care Med. 2016;44(2):390-438.

137. Nielsen N: Target temperature management after out-of-hospital cardiac arrest. Circulation 2011, 124(21 suppl. 1).

138. Perbet S, Mongardon N, Dumas F, Bruel C, Lemiale V, Mourvillier B, Carli P, Varenne O, Mira JP, Wolff M, et al. Early-onset pneumonia after cardiac arrest: characteristics, risk factors and influence on prognosis. Am J Resp Crit Care. 2011;184(9):1048-54.

139. Hashiguchi N, Shiozaki T, Ogura H, Tanaka H, Koh T, Noborio M, Fugita K, Akimau P, Kuwagata Y, Shimazu T, et al. Mild hypothermia reduces expression of heat shock protein 60 in leukocytes from severely head-injured patients. J Trauma. 2003;55(6): 1054-60.

140. Fries MS, C.;Brucken, D.;Rossaint, R.;Kuhlen, R.: Influence of mild therapeutic hypothermia on the inflammatory response after successful resuscitation from cardiac arrest. J Crit Care 2009, 24(3):453-457.

141. Jacob M, Hassager C, Bro-Jeppesen J, Ostrowski SR, Thomsen JH, Wanscher M, Johansson PI, Winther-Jensen M, Kjærgaard J. The effect of targeted temperature management on coagulation parameters and bleeding events after out-of-hospital cardiac arrest of presumed cardiac cause. Resuscitation. 2015;96:260-7. 
142. Maekawa T, Yamashita S, Nagao S, Hayashi N, Ohashi Y. Prolonged mild therapeutic hypothermia versus fever control with tight hemodynamic monitoring and slow rewarming in patients with severe traumatic brain injury: a randomized controlled trial. J Neurotrauma. 2015;32(7):422-9.

143. Perrone S, Szabo M, Bellieni CV, Longini M, Bango M, Kelen D, Treszl A, Negro S, Tataranno ML, Buonocore G. Whole body hypothermia and oxidative stress in babies with hypoxicischemic brain injury. Pediatr Neurol. 2010;43(4):236-40.

144. Staykov D, Wagner I, Volbers B, Doerfler A, Schwab S, Kollmar R. Mild prolonged hypothermia for large intracerebral hemorrhage. Neurocrit Care. 2013;18(2):178-83.

145. Tokutomi T, Miyagi T, Morimoto K, Karukaya T, Shigemori M. Effect of hypothermia on serum electrolyte, inflammation, coagulation, and nutritional parameters in patients with severe traumatic brain injury. Neurocrit Care. 2004;1(2):171-82.

146. Ishikawa K, Tanaka H, Shiozaki T, Takaoka M, Ogura H, Kishi M, Shimazu T, Sugimoto H. Characteristics of infection and leukocyte count in severely head-injured patients treated with mild hypothermia. J Trauma. 2000;49(5):912-22.

147. Rhodes A, Evans LE, Alhazzani W, Levy MM, Antonelli M, Ferrer R, Kumar A, Sevransky JE, Sprung CL, Nunnally ME, et al. Surviving Sepsis campaign: international guidelines for management of sepsis and septic shock: 2016. Intensive Care Med. 2017;43(3):304-77.

148. O'Grady NP, Barie PS, Bartlett JG, Bleck T, Carroll K, Kalil AC, Linden P, Maki DG, Nierman D, Pasculle W, et al. Guidelines for evaluation of new fever in critically ill adult patients: 2008 update from the American college of critical care medicine and the infectious diseases society of America. Crit Care Med. 2008;36(4):1330-49.

149. Mirzoyev SA, McLeod CJ, Bunch TJ, Bell MR, White RD. Hypokalemia during the cooling phase of therapeutic hypothermia and its impact on arrhythmogenesis. Resuscitation. 2010;81(12):1632-6.

150. Koht A, Cane R, Cerullo LJ. Serum potassium levels during prolonged hypothermia. Intensive Care Med. 1983;9(5):275-7.

151. Eastwood GM, Suzuki S, Lluch C, Schneider AG, Bellomo R. A pilot assessment of alpha-stat vs pH-stat arterial blood gas analysis after cardiac arrest. J Crit Care. 2015;30(1):138-44.

152. Zeiner A, Sunder-Plassmann G, Sterz F, Holzer M, Losert H, Laggner AN, Mullner M. The effect of mild therapeutic hypothermia on renal function after cardiopulmonary resuscitation in men. Resuscitation. 2004;60(3):253-61.

153. Zhao QJ, Zhang XG, Wang LX. Mild hypothermia therapy reduces blood glucose and lactate and improves neurologic outcomes in patients with severe traumatic brain injury. J Crit Care. 2011;26(3):311-5.

154. Cueni-Villoz N, Devigili A, Delodder F, Cianferoni S, Feihl F, Rossetti AO, Eggimann P, Vincent JL, Taccone FS, Oddo M. Increased blood glucose variability during therapeutic hypothermia and outcome after cardiac arrest. Crit Care Med. 2011;39(10):2225-31.

155. Ettleson MD, Arguello V, Wallia A, Arguelles L, Bernstein RA, Molitch ME. Hyperglycemia and insulin resistance in cardiac arrest patients treated with moderate hypothermia. J Clin Endocrinol Metab. 2014;99(10):E2010-4.

156. Sunjic KM, Webb AC, Sunjic I, Pala Creus M, Folse SL. Pharmacokinetic and other considerations for drug therapy during targeted temperature management. Crit Care Med. 2015;43(10):2228-38.

157. Heier T, Clough D, Wright PM, Sharma ML, Sessler DI, Caldwell JE. The influence of mild hypothermia on the pharmacokinetics and time course of action of neostigmine in anesthetized volunteers. Anesthesiology. 2002;97(1):90-5.
158. Souckova L, Opatrilova R, Suk P, Cundrle I Jr, Pavlik M, Zvonicek V, Hlinomaz O, Sramek V. Impaired bioavailability and antiplatelet effect of high-dose clopidogrel in patients after cardiopulmonary resuscitation (CPR). Eur J Clin Pharmacol. 2013;69(3):309-17.

159. Kaufmann J, Wellnhofer E, Stockmann H, Graf K, Fleck E, Schroeder T, Stawowy P, Storm C. Clopidogrel pharmacokinetics and pharmacodynamics in out-of-hospital cardiac arrest patients with acute coronary syndrome undergoing target temperature management. Resuscitation. 2016;102:63-9.

160. Bednar F, Kroupa J, Ondrakova M, Osmancik P, Kopa M, Motovska Z. Antiplatelet efficacy of P2Y12 inhibitors (prasugrel, ticagrelor, clopidogrel) in patients treated with mild therapeutic hypothermia after cardiac arrest due to acute myocardial infarction. J Thromb Thrombolysis. 2016;41(4):549-55.

161. Joffre JV, O.; Bougouin, W.; Rosencher, J.; Mira, J.P.: Stent thrombosis: an increased adverse sevent after angioplasty following resuscitated cardiac arrest. Resuscitation 2014, 85:769-773.

162. Tilemann LMS, J.;Zelniker, T.;Chorianopoulos, E.;Giannitsis, E.;Katus, H. A.;Muller, O. J.;Preusch, M.: Efficacy of enteral ticagrelor in hypothermic patients after out-of-hospital cardiac arrest. Clin Res Cardiol 2016, 105(4):332-340.

163. Steblovnik K, Blinc A, Mijovski MB, Fister M, Mikuz U, Noc M. Ticagrelor versus clopidogrel in comatose survivors of outof-hospital cardiac arrest undergoing percutaneous coronary intervention and hypothermia: a randomized study. Circulation. 2016;134(25):2128-30.

164. Fukuoka N, Aibiki M, Tsukamoto T, Seki K, Morita S. Biphasic concentration change during continuous midazolam administration in brain-injured patients undergoing therapeutic moderate hypothermia. Resuscitation. 2004;60(2):225-30.

165. Bjelland TW, Klepstad P, Haugen BO, Nilsen T, Salvesen O, Dale O. Concentrations of remifentanil, propofol, fentanyl, and midazolam during rewarming from therapeutic hypothermia. Acta Anaesthesiol Scand. 2014;58(6):709-15.

166. Bjelland TW, Klepstad P, Haugen BO, Nilsen T, Dale O. Effects of hypothermia on the disposition of morphine, midazolam, fentanyl, and propofol in intensive care unit patients. Drug Metab Dispos. 2013;41(1):214-23.

167. Leslie K, Sessler DI, Bjorksten AR, Moayeri A. Mild hypothermia alters propofol pharmacokinetics and increases the duration of action of atracurium. Anesth Analg. 1995;80(5):1007-14.

168. Tortorici MA, Kochanek PM, Poloyac SM. Effects of hypothermia on drug disposition, metabolism, and response: a focus of hypothermia-mediated alterations on the cytochrome P450 enzyme system. Crit Care Med. 2007;35(9):2196-204.

169. Caldwell JE, Heier T, Wright PM, Lin S, McCarthy G, Szenohradszky J, Sharma ML, Hing JP, Schroeder M, Sessler DI. Temperature-dependent pharmacokinetics and pharmacodynamics of vecuronium. Anesthesiology. 2000;92(1):84-93.

170. Beaufort AM, Wierda JM, Belopavlovic M, Nederveen PJ, Kleef UW, Agoston S. The influence of hypothermia (surface cooling) on the time-course of action and on the pharmacokinetics of rocuronium in humans. Eur J Anesth Suppl. 1995;11(Suppl):95-106.

171. Iida Y, Nishi S, Asada A. Effect of mild therapeutic hypothermia on phenytoin pharmacokinetics. Ther Drug Monit. 2001;23(3):192-7.

172. Bagna FC, Pitoni S, Andrews PJD. Therapeutic mild hypothermia and the pharmacokinetics of drugs in Trauma Brain Injury (TBI) patients with a focus on sedation, anticonvulsant and antibiotic therapy. Open Crit Care Med J. 2013;6(1):31-8.

173. Empey PE, Velez de Mendizabal N, Bell MJ, Bies RR, Anderson KB, Kochanek PM, Adelson PD, Poloyac SM, Pediatric TBICHI: Therapeutic hypothermia decreases phenytoin 
elimination in children with traumatic brain injury. Crit Care Med 2013, 41(10):2379-2387.

174. Wahby KA, Jhajhria S, Dalal BD, Soubani AO. Heparin dosing in critically ill patients undergoing therapeutic hypothermia following cardiac arrest. Resuscitation. 2014;85(4):533-7.

175. Fevold RT, Leung YT, Garofoli AC, White RD, Barsness GW, Dierkhising RA, Ou NN. Heparin dose adjustment required to maintain goal-activated partial thromboplastin time during therapeutic hypothermia. J Crit Care. 2015;30(3):574-8.

176. Polderman KH, Herold I. Therapeutic hypothermia and controlled normothermia in the intensive care unit: practical considerations, side effects, and cooling methods. Crit Care Med. 2009;37(3):1101-20.

177. Jeppesen AN, Kirkegaard H, Ilkjær S, Hvas AM. Influence of temperature on thromboelastometry and platelet aggregation in cardiac arrest patients undergoing targeted temperature management. Crit Care. 2016;20(1):118.

178. Chih-Hung W, Nai-Chuan C, Min-Shan T, Ping-Hsun Y, An-Yi W, Wei-Tien C, Chien-Hua H, Wen-Jone C, Wang C-H, Chen $\mathrm{N}-\mathrm{C}$, et al. Therapeutic hypothermia and the risk of hemorrhage: a systematic review and meta-analysis of randomized controlled trials. Medicine. 2015;94(47):1-8.

179. Stockmann H, Krannich A, Schroeder T, Storm C. Therapeutic temperature management after cardiac arrest and the risk of bleeding: systematic review and meta-analysis. Resuscitation. 2014;85(11):1494-503.

180. Wu TC, Grotta JC. Hypothermia for acute ischaemic stroke. Lancet Neurol. 2013;12(3):275-84.

181. Todd MM, Hindman BJ, Clarke WR, Torner JC. Intraoperative hypothermia for aneurysm surgery trial I: mild intraoperative hypothermia during surgery for intracranial aneurysm. N Engl $\mathrm{J}$ Med. 2005;352(2):135-45.

182. Seule M, Keller E. Hypothermia after aneurysmal subarachnoid hemorrhage. Crit Care. 2012;16(Suppl 2):A16.

183. Stiller K. Physiotherapy in intensive care: an updated systematic review. Chest. 2013;144(3):825-47.

184. Hodgson CL, Berney S, Harrold M, Saxena M, Bellomo R. Clinical review: early patient mobilization in the ICU. Crit Care. 2013;17(1):207.

185. Cumming TB, Thrift AG, Collier JM, Churilov L, Dewey HM, Donnan GA, Bernhardt J. Very early mobilization after stroke fast-tracks return to walking: further results from the phase II AVERT randomized controlled trial. Stroke. 2011;42(1):153-8.

186. Jarrah S, Dziodzio J, Lord C, Fraser GL, Lucas L, Riker RR, Seder DB. Surface cooling after cardiac arrest: effectiveness, skin safety, and adverse events in routine clinical practice. Neurocrit Care. 2011;14(3):382-8.

187. Mayer SA, Kowalski RG, Presciutti M, Ostapkovich ND, McGann E, Fitzsimmons BF, Yavagal DR, Du YE, Naidech AM, Janjua NA, et al. Clinical trial of a novel surface cooling system for fever control in neurocritical care patients. Crit Care Med. 2004;32(12):2508-15.

188. Varon J, Acosta P, Wintz R, Mendoza N. Unusual side effect from hydrogel pads during therapeutic hypothermia. Resuscitation. 2008;78(3):248-9.

189. Leary M, Cinousis MJ, Mikkelsen ME, Gaieski DF, Abella BS, Fuchs BD. The association of body mass index with time to target temperature and outcomes following post-arrest targeted temperature management. Resuscitation. 2014;85(2):244-7.

190. De Georgia MA, Krieger DW, Abou-Chebl A, Devlin TG, Jauss M, Davis SM, Koroshetz WJ, Rordorf G, Warach S. Cooling for
Acute Ischemic Brain Damage (COOL AID): a feasibility trial of endovascular cooling. Neurology. 2004;63(2):312-7.

191. Piironen K, Tiainen M, Mustanoja S, Kaukonen KM, Meretoja A, Tatlisumak T, Kaste M. Mild hypothermia after intravenous thrombolysis in patients with acute stroke: a randomized controlled trial. Stroke. 2014;45(2):486-91.

192. Tiainen M, Parikka HJ, Makijarvi MA, Takkunen OS, Sarna SJ, Roine RO. Arrhythmias and heart rate variability during and after therapeutic hypothermia for cardiac arrest. Crit Care Med. 2009;37(2):403-9.

193. Gluckman PD, Wyatt JS, Azzopardi D, Ballard R, Edwards AD, Ferriero DM, Polin RA, Robertson CM, Thoresen M, Whitelaw A, et al. Selective head cooling with mild systemic hypothermia after neonatal encephalopathy: multicentre randomised trial. Lancet. 2005;365(9460):663-70.

194. Moler FW, Silverstein FS, Holubkov R, Slomine BS, Christensen JR, Nadkarni VM, Meert KL, Browning B, Pemberton VL, Page K, et al. Therapeutic hypothermia after in-hospital cardiac arrest in children. N Engl J Med. 2017;376(4):318-29.

195. Bourdages M, Bigras JL, Farrell CA, Hutchison JS, Lacroix J. Canadian critical care trials G: cardiac arrhythmias associated with severe traumatic brain injury and hypothermia therapy. Pediatr Crit Care Med. 2010;11(3):408-14.

196. Eicher DJ, Wagner CL, Katikaneni LP, Hulsey TC, Bass WT, Kaufman DA, Horgan MJ, Languani S, Bhatia JJ, Givelichian LM, et al. Moderate hypothermia in neonatal encephalopathy: safety outcomes. Pediatr Neurol. 2005;32(1):18-24.

197. Beca J, McSharry B, Erickson S, Yung M, Schibler A, Slater A, Wilkins B, Singhal A, Williams G, Sherring C, et al. Hypothermia for traumatic brain injury in children-A phase II randomized controlled trial. Crit Care Med. 2015;43(7):1458-66.

198. Jacobs SE, Morley CJ, Inder TE, Stewart MJ, Smith KR, McNamara PJ, Wright IM, Kirpalani HM, Darlow BA, Doyle $\mathrm{LW}$, et al. Whole-body hypothermia for term and near-term newborns with hypoxic-ischemic encephalopathy: a randomized controlled trial. Arch Pediatr Adolesc Med. 2011;165(8):692-700.

199. Merchant RM, Becker LB, Abella BS, Asch DA, Groeneveld PW. Cost-effectiveness of therapeutic hypothermia after cardiac arrest. Circ Cardiovasc Qual Outcomes. 2009;2(5):421-8.

200. Gajarski RJ, Smitko K, Despres R, Meden J, Hutton DW. Costeffectiveness analysis of alternative cooling strategies following cardiac arrest. SpringerPlus. 2015;4:427.

201. Argibay-Lago A, Fernandez-Rodriguez D, Ferrer-Sala N, PrietoRobles C, Hernanz-del Rio A, Castro-Rebollo P. Evaluation of nurse workload in patients undergoing therapeutic hypothermia. Enferm Clin. 2014;24(6):323-9.

202. Krawczyk P, Kolodziej G, Szpyra B, Andres J. Implementation of therapeutic hypothermia after cardiac arrest in intensive care units in Poland. Kardiol Pol. 2013;71(3):270-4.

203. Olson DM, Kelly AP, Washam NC, Thoyre SM. Critical care nurses' workload estimates for managing patients during induced hypothermia. Nurs Crit Care. 2008;13(6):305-9.

204. Toma A, Bensimon CM, Dainty KN, Rubenfeld GD, Morrison LJ, Brooks SC. Perceived barriers to therapeutic hypothermia for patients resuscitated from cardiac arrest: a qualitative study of emergency department and critical care workers. Crit Care Med. 2010;38(2):504-9.

205. Vaga A, Busch M, Karlsen TE, Nilsen OB, Soreide E. A pilot study of key nursing aspects with different cooling methods and devices in the ICU. Resuscitation. 2008;76(1):25-30. 